\title{
Problems in the Differential Diagnosis of Endometrial Hyperplasia and Carcinoma
}

Steven G. Silverberg, M.D.

Department of Pathology, University of Maryland Medical Center, Baltimore, Maryland

The differential diagnosis of endometrial hyperplasia and well-differentiated endometrioid adenocarcinoma is complicated not only by the resemblance of these lesions to each other, but also by their tendency to be overdiagnosed (particularly hyperplasia) on the background of polyps, endometritis, artifacts, and even normally cycling endometrium. Atypical hyperplasia may also be overdiagnosed when epithelial metaplastic changes occur in simple or complex hyperplasia without atypia. Lowgrade adenocarcinomas are best recognized by architectural evidence of stromal invasion, usually in the form of stromal disappearance, desmoplasia, necrosis, or combinations of these findings between adjacent glands. Endometrioid adenocarcinomas are usually Type 1 cancers associated with manifestations of endogenous or exogenous hyperestrogenic stimulation and a favorable prognosis. Subtypes include adenocarcinomas with squamous differentiation and secretory, ciliated cell and villoglandular variants. Rules and pitfalls in the grading of endometrioid adenocarcinomas and the estimation and reporting of myometrial invasion are presented.

KEY WORDS: Differential diagnosis, Endometrial carcinoma, Endometrial hyperplasia, Grading, Myoinvasion.

Mod Pathol 2000;13(3):309-327

The purpose of this article is to review the relationships between hyperplasia and adenocarcinoma of the endometrium, with an emphasis on the differential diagnostic problems both between these two lesions and between them and other entities that enter into the differential diagnostic picture. However, differential diagnosis is not the only relationship between endometrial hyperplasia and carcinoma. During the course of this review, we briefly

Copyright (C) 2000 by The United States and Canadian Academy of Pathology, Inc.

VOL. 13, NO. 3, P. 309, 2000 Printed in the U.S.A.

Date of acceptance: November 8, 1999.

Address reprint requests to: Steven G. Silverberg, M.D., Department of Pathology, University of Maryland Medical Center, 22 S. Greene Street, Baltimore, MD 21201; fax: 410-328-0081. consider the questions of the progression of endometrial hyperplasia (and specifically its atypical variant) to carcinoma, as well as the prognostic effect of the presence of endometrial hyperplasia in cases of endometrial carcinoma, and the biologic significance of carcinoma that arises in the presence or absence of hyperplasia. The last of these topics, however, is considered in much greater detail in the article by Sherman (1) in this issue.

There are four possible approaches to making the differential diagnosis between atypical endometrial hyperplasia and well-differentiated endometrioid adenocarcinoma of the endometrium. These approaches may be summarized briefly as follows: (1) adenocarcinoma in situ, (2) endometrial intraepithelial neoplasia (EIN), (3) nonhistologic techniques, and (4) so-called "routine" light microscopy.

The oldest of these approaches is the first, in which it is assumed that there must be an entity, conveniently named adenocarcinoma in situ, that is intermediate between the most severe atypical hyperplasia and the earliest focal change recognizable as invasive adenocarcinoma. Probably the most effective rebuttal of this concept for diagnostic purposes was made by Professor Harold Fox, who stated, "A true adenocarcinoma in situ of the endometrium is one in which the glands have undergone neoplastic change but in which there is no invasion of the endometrial stroma. It is doubtful if any adenocarcinoma of this type exists or if it could be recognized even if it did exist" (2). Because of this and similar objections, the term "adenocarcinoma in situ" does not appear in the current International Society of Gynecological Pathologists (ISGP), International Federation of Gynecology and Obstetrics (FIGO), and World Health Organization (WHO) classifications (which are identical) of endometrial neoplasia and preneoplasia (3).

Another approach that has had and continues to have its proponents is the use of the term "endometrial intraepithelial neoplasia (EIN)" to encompass lesions that span from atypical complex hyperplasia to focal low-grade endometrioid adenocarcinoma (4). The assumption is that reliable and reproducible criteria for distinguishing these two entities do not exist, and that they should therefore be combined under 
the one rubric of EIN. This approach has much to recommend it, but the problem is that decisions must still be made by the diagnostic pathologist. Thus, diagnostic problems will still exist at both the lower end (complex hyperplasia without atypia versus atypical complex hyperplasia) and the upper end (focal lowgrade endometrioid adenocarcinoma versus a more extensive or higher-grade adenocarcinoma) of the EIN spectrum. Thus, I assert that the EIN terminology does not solve our diagnostic problems but merely adds a new term that further confuses the clinicians who care for patients with these diseases.

The third possibility in dealing with these differential diagnostic problems is to admit defeat at the light microscopic level and search for various nonhistologic techniques that might enable making a distinction between an atypical hyperplasia and welldifferentiated adenocarcinoma. However, to date, this search has proved elusive, as no ploidy, histochemical, immunohistochemical, or molecular studies have yet demonstrated reproducible differences between these two entities (5-18). If anything, these studies have supported the EIN concept, as most abnormalities found in low-grade endometrioid carcinomas can also be demonstrated in more or less equal proportions of atypical hyperplasias.

Finally, we are left with the fourth approach, which is the attempt to distinguish between atypical complex hyperplasia and well-differentiated adenocarcinoma on purely histologic grounds. This distinction, therefore, forms a major part of the discussion that follows.

\section{CLASSIFICATION AND DIFFERENTIAL DIAGNOSIS OF ENDOMETRIAL HYPERPLASIAS}

Before proceeding to the discussion of the differential diagnosis between the most marked forms of atypical complex hyperplasia and the lowest-grade endometrioid adenocarcinoma, we must first consider the full spectrum of endometrial hyperplasias. The new ISGP, FIGO, and WHO classification divides the endometrial hyperplasias into those that are and those that are not atypical, and each of these classifications is divided into simple and complex variants (3). It is important to realize that each of these forms (simple hyperplasia without atypia, complex hyperplasia without atypia, atypical simple hyperplasia, and atypical complex hyperplasia) must be distinguished not only from the other forms and from adenocarcinoma but also from a large number of other appearances of the endometrium, most of which are not considered hyperplastic. In addition, each of the forms of hyperplasia has a somewhat different differential diagnostic spectrum. It is important for the practicing pathologist to appreciate this spectrum, because endometrial hyperplasias are among the most commonly overdiagnosed lesions in diagnostic surgical pathology. In a classic study, Winkler et al. (19) analyzed 100 consecutive cases referred to their laboratory with the diagnosis of endometrial hyperplasia. Remarkably, they found that the exact diagnosis made by the referring pathologist was confirmed in only 24 of these cases; among the others, the diagnosis was downgraded in 69, upgraded in only 3 , and uncertain in the remaining 4 . The most common downgrading was done for polyps (25 cases), normal cycling endometrium (17 cases), and less severe forms of hyperplasia than originally diagnosed (16 cases). It was also noted in this study that nine cases had metaplastic changes that might have contributed to the diagnostic difficulty, and three had endometritis. My own anecdotal experience has been very similar, both in the frequency of overdiagnosed hyperplasia and in the reasons for it. Other studies have also commented on problems with reproducibility of diagnostic criteria among the hyperplasias, with particular emphasis on atypical hyperplasia $(20,21)$.

The histologic appearance of simple hyperplasia is that of an endometrium that is first increased in volume and second qualitatively different from normal cycling endometrium. Both the glands and the stroma participate in this process so that the glands are not particularly crowded. The glands are usually uniformly rounded but may show marked variation in shape, with many cystically dilated forms (Fig. 1). Their lining epithelium is pseudostratified to modestly stratified, contains occasional mitotic figures, and, by definition, lacks nuclear atypia. The stroma is also active, is uniformly cellular, may be mitotically active, and contains evenly distributed small blood vessels resembling the spiral arterioles seen in late secretory endometrium or those seen in low-grade endometrial stromal tumors (Figs. 1 and 2).

Because the most prominent feature noted in simple hyperplasia at low-power examination is often the cystically dilated glands, the differential diagnosis includes both cystic atrophy and endometrial polyps. In the former, the distinction is easily made because the glands are lined by reduced rather than proliferated epithelium and the stroma is dense and appears atrophic. Polyps are often more of a problem, unless they present as large, spherical, cohesive masses obviously covered on three surfaces by epithelium (Fig. 3). However, the majority of endometrial polyps encountered in practice are of microscopic size and are best recognized by finding a cohesive fragment of endometrium that differs from the surrounding endometrial tissue in a curettage specimen. Both the cohesiveness and the difference from surrounding tissue are best explained by the polypoid stroma, which almost always shows at least some (and oc- 


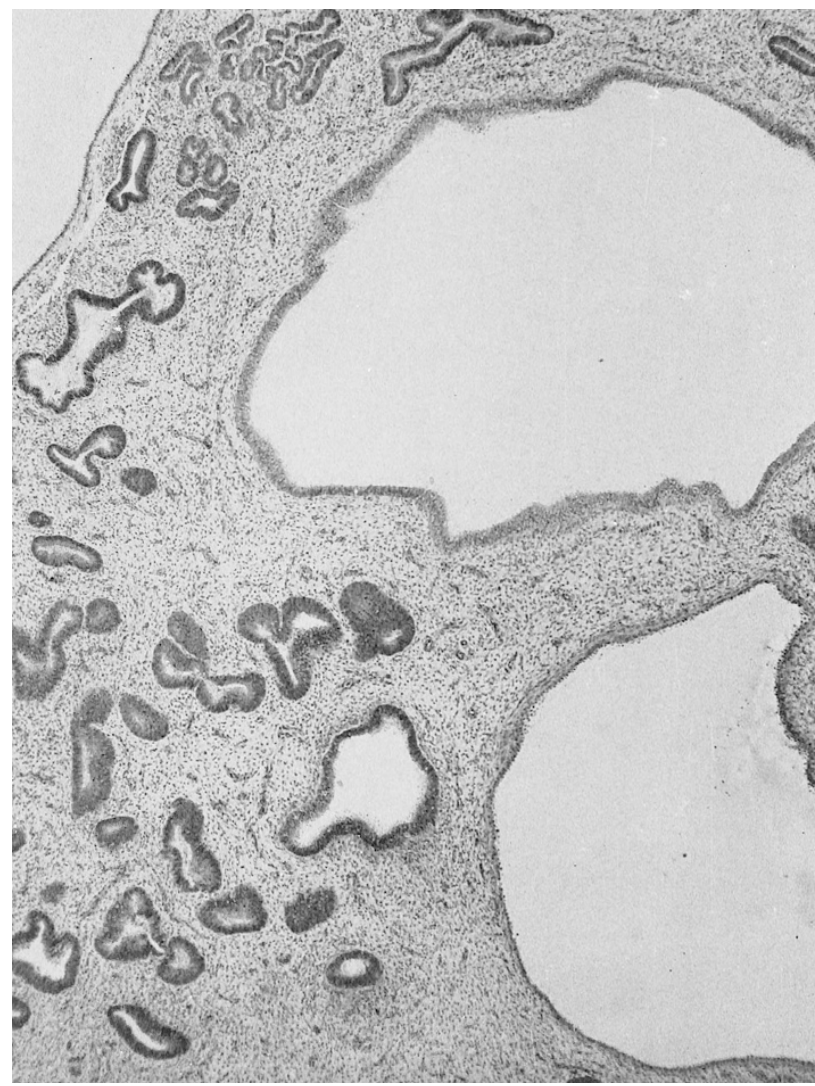

FIGURE 1. Simple hyperplasia. Glands and stroma both are active, glands are irregularly distributed, and some are cystically dilated. Note uniformly distributed blood vessels in stroma. casionally extensive) fibrosis (Fig. 3). This fibrotic stroma is markedly different from that of a simple hyperplasia, as are the typically dilated, thickwalled blood vessels different from the small, spiral arteriole-like vessels of a simple hyperplasia (Fig. 4).

Also part of the differential diagnosis of simple hyperplasia are normal cycling endometrium, disordered proliferative phase, various compression artifacts, and chronic endometritis. Normal endometrium is actually more commonly confused with complex hyperplasia, and the distinction is discussed in a later section. The term "disordered proliferative endometrium" has been used in a number of ways and is somewhat difficult to define. However, one common usage is for an endometrial appearance that is hyperplastic but without an increase in endometrial volume (22). This distinction is difficult, if not impossible, to make in an outpatient biopsy specimen and should therefore be reserved for formal curettage and hysterectomy specimens. Perhaps a better usage refers to a proliferative phase endometrium that does not seem appropriate for any one time in the menstrual cycle but is not abnormal enough to be considered hyperplastic. Thus, an essentially normal proliferative phase endometrium with a few widely scattered cystic glands would better be called "disordered proliferative" than simple hyperplasia. Much

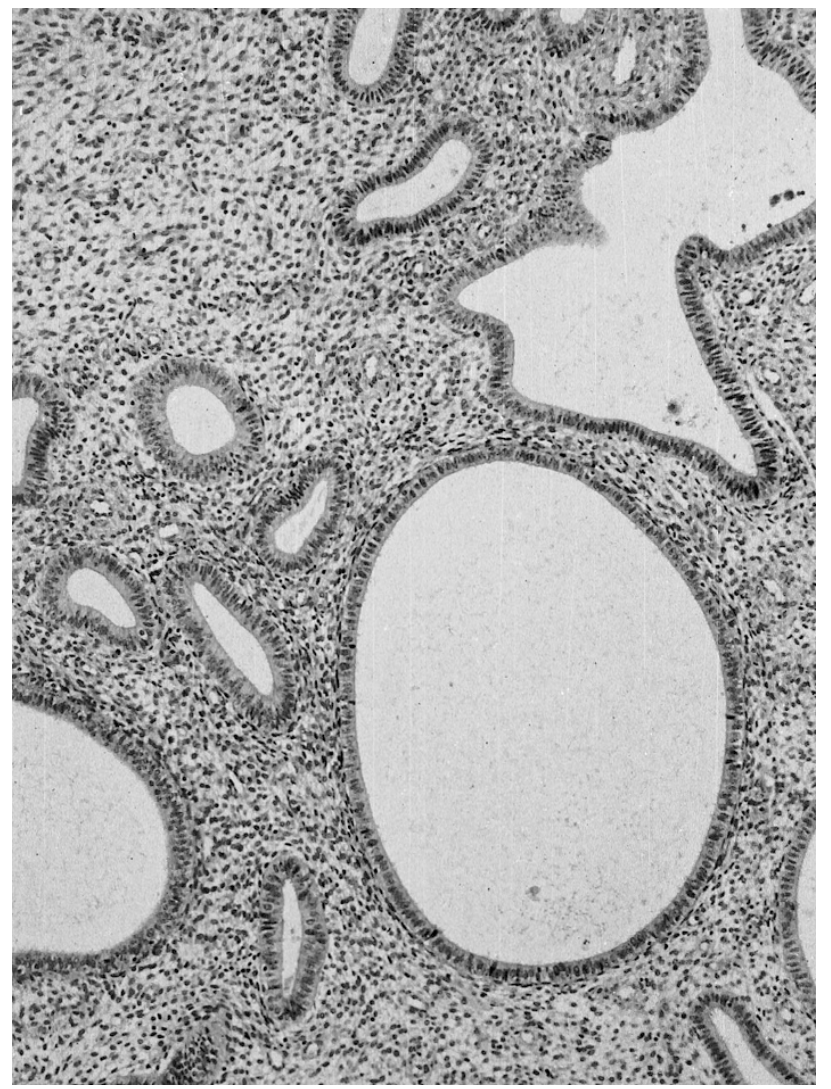

FIGURE 2. Simple hyperplasia. Balance between proliferation of glands and stroma is again noted. Most of the glands illustrated here are round, although some are cystically dilated. All are lined by proliferative-looking endometrium. Small blood vessels are uniformly distributed in the cellular stroma.

more common than patterns such as these, however, is normal proliferative endometrium displaying various fixation and compression artifacts. Both doublebarreled lumina and artifactual glandular approximation fall into this category and should be clearly distinguished from simple or complex hyperplasia (Figs. 5 and 6). It is worthwhile to remember that hyperplasia is virtually always a diffuse endometrial lesion, whereas these artifactual changes are invariably focal.

Chronic endometritis is also an occasional source of overdiagnosis of endometrial hyperplasia, as the inflamed endometrium may develop reactive glandular changes (as in any other glandular organ), which can result in glandular crowding, abnormal gland shapes, and occasional variable degrees of cytologic atypia. The most important clues to correct diagnosis are the presence of stromal plasma cells and a degree of stromal spindling and edema, as well as neutrophils in the surface epithelium.

\section{Complex Hyperplasia}

Complex hyperplasia is distinguished from simple hyperplasia by a greater degree of glandular proliferation, crowding out the intervening stroma, 


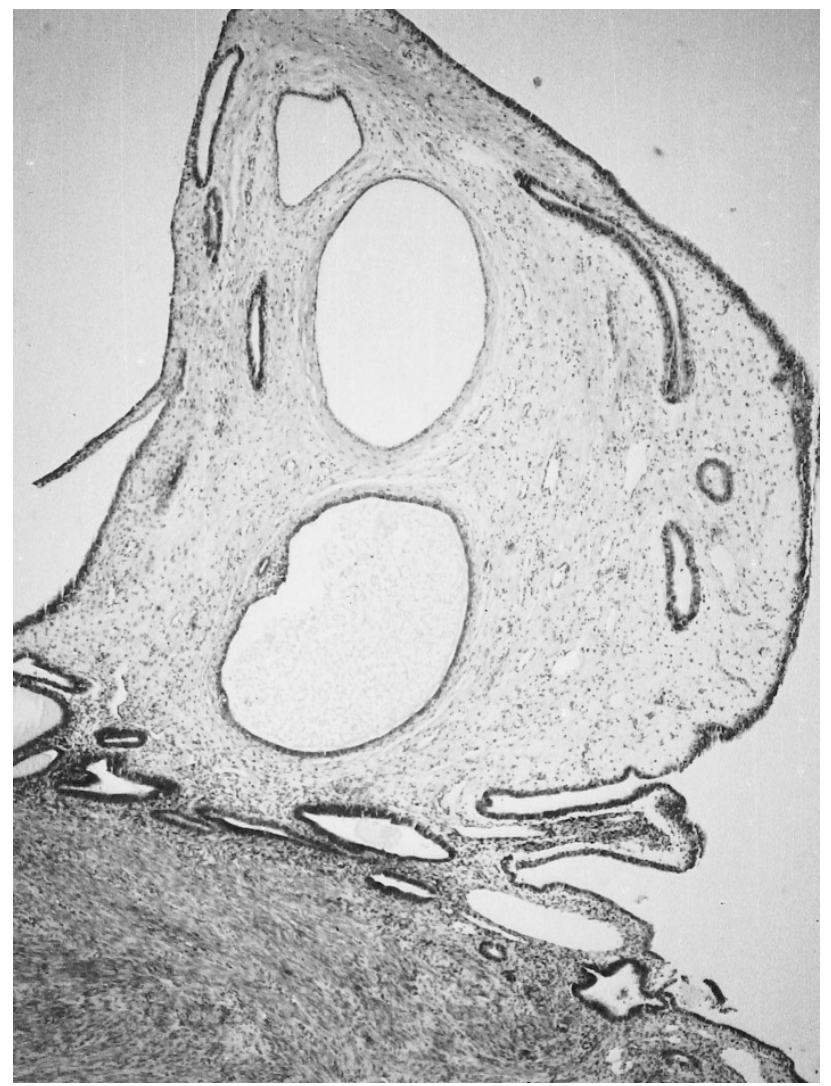

FIGURE 3. Endometrial polyp in hysterectomy specimen. This specimen clearly demonstrates a polypoid projection protruding from the endometrial surface, which is covered on three surfaces by endometrial epithelium. Note dilated glands, fibrotic stroma, and scattered dilated thick-walled blood vessels.

and often eventuating in the presence of glands that are markedly variable in size and shape, some with totally anarchic side buds and outpouchings (Fig. 7). As in simple hyperplasia, nuclear atypia is absent. The stroma between adjacent glands may be reduced to only a few cells, but by definition, some normal stromal cells are invariably observable. The differential diagnosis includes all of the entities for simple hyperplasia, as well as simple hyperplasia itself. The borderline between simple and complex hyperplasia is sometimes difficult to distinguish. The differential diagnosis with atypical hyperplasia depends on the presence of cytologic atypia in the latter condition, as will be discussed. The differential diagnosis with carcinoma depends on the continued presence of stroma between the glands in complex or atypical complex hyperplasia.

An additional entity unique to the differential diagnosis of complex and atypical complex hyperplasia is the atypical polypoid adenomyoma or, as it has been called more recently, atypical polypoid adenomyofibroma (23). This lesion is observed predominantly in premenopausal and perimenopausal women and develops as a solitary polypoid lesion, most commonly in the lower uterine segment and endocervix. It is characterized microscopically by

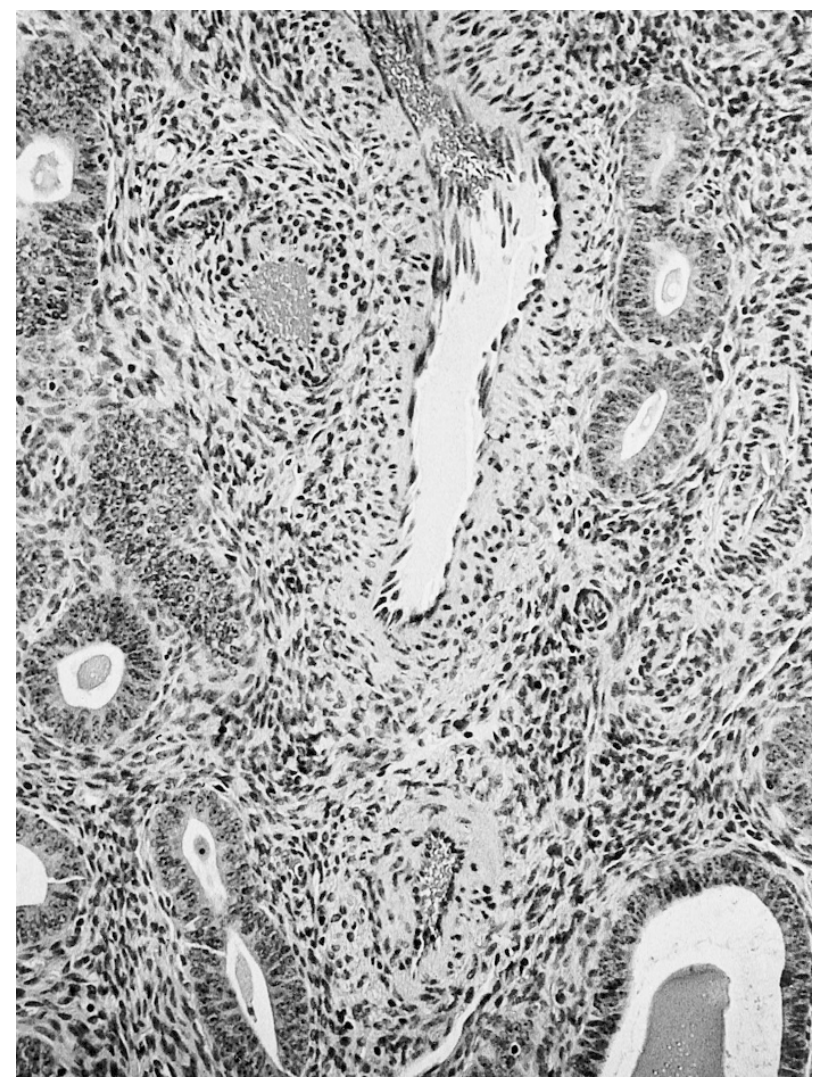

FIGURE 4. Endometrial polyp. At the center of this figure appear several profiles of dilated thick-walled blood vessels, characteristic of endometrial polyps. In this field, stromal fibrosis is slight compared with Figure 3, and the endometrial glands appear proliferative.

an intimate admixture of benign endometrial glands and a stroma consisting predominantly or exclusively of equally benign-looking smooth muscle, which may be admixed with or even largely replaced by fibroblastic tissue (Fig. 8). The glands invariably exhibit architectural atypia similar to that of complex hyperplasia and may show cytologic atypia as well. Extensive squamous or morular metaplasia is usually found in the epithelial component. The smooth muscle component consists of swirling and interlacing fascicles, which are intimately associated with the lesional glands. Although this lesion is easily diagnosable in a hysterectomy specimen, its diagnosis may be quite problematic in a curettage or biopsy. The most common mistaken diagnosis is atypical complex hyperplasia, but occasionally, atypical polypoid adenomyoma is confused with an endometrial carcinoma invading the myometrium. However, myoinvasion is rarely seen in curettage specimens, the glands of atypical polypoid adenomyoma lack cytological and architectural features of malignancy, and the smooth muscle component exhibits a cellularity and swirling pattern not seen in normal myometrium and lacks the usual desmoplastic stromal response to invasive cancer. 


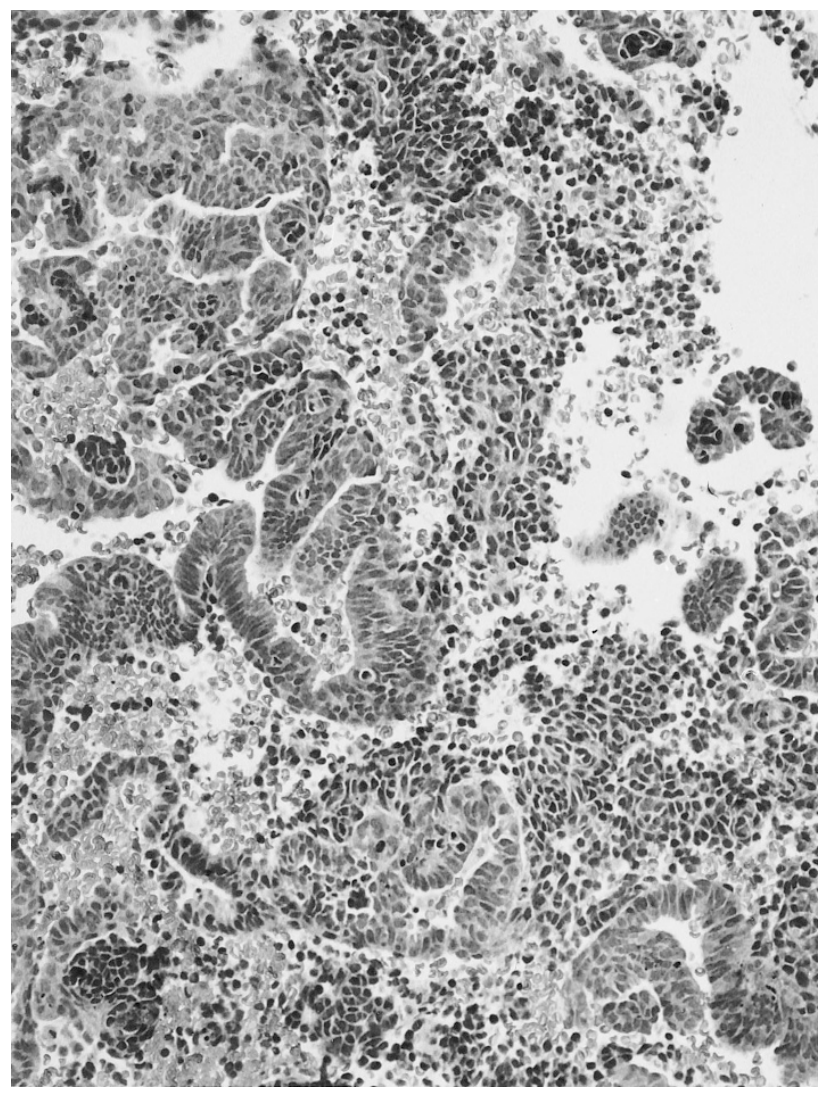

FIGURE 5. Curettage specimen from a perimenopausal patient with abnormal bleeding. Stroma is largely hemorrhagic and necrotic, leading to close approximation of endometrial glandular epithelium, simulating a hyperplasia or carcinoma. This specimen is probably from an anovulatory cycle and is thus lacking in secretory changes, further complicating the correct interpretation of this specimen as totally benign.

\section{Atypical Hyperplasia}

In atypical hyperplasia, the architectural anomalies described above for either simple or complex hyperplasia are embellished by cytologic atypia. The main features are cellular dyspolarity, irregular stratification, and anisocytosis, accompanied by nuclear rounding (as compared with the uniform columnar nuclei of hyperplasias without atypia), nucleomegaly, hyperchromatism, chromatin clumping, and enlarged nucleoli (Fig. 9). Many cases are also characterized by marked cytoplasmic eosinophilia, but this is not a prerequisite for the diagnosis. Because the atypia within a hyperplasia is usually focal, however, the cytoplasmic eosinophilia may be the first finding to alert the pathologist to the atypical glands. An additional low-power finding that may be useful is the presence of eosinophilic necrotic debris within the atypical glands of a hyperplastic process.

Atypical hyperplasias are more often complex than simple, and in my experience, atypical simple hyperplasia is an uncommon endometrial lesion. The presence or absence of atypia within a hyperplastic process is one of the least reproducible diagnostic criteria in the spectrum of endometrial hyperplasias and carcinomas; therefore, it is always

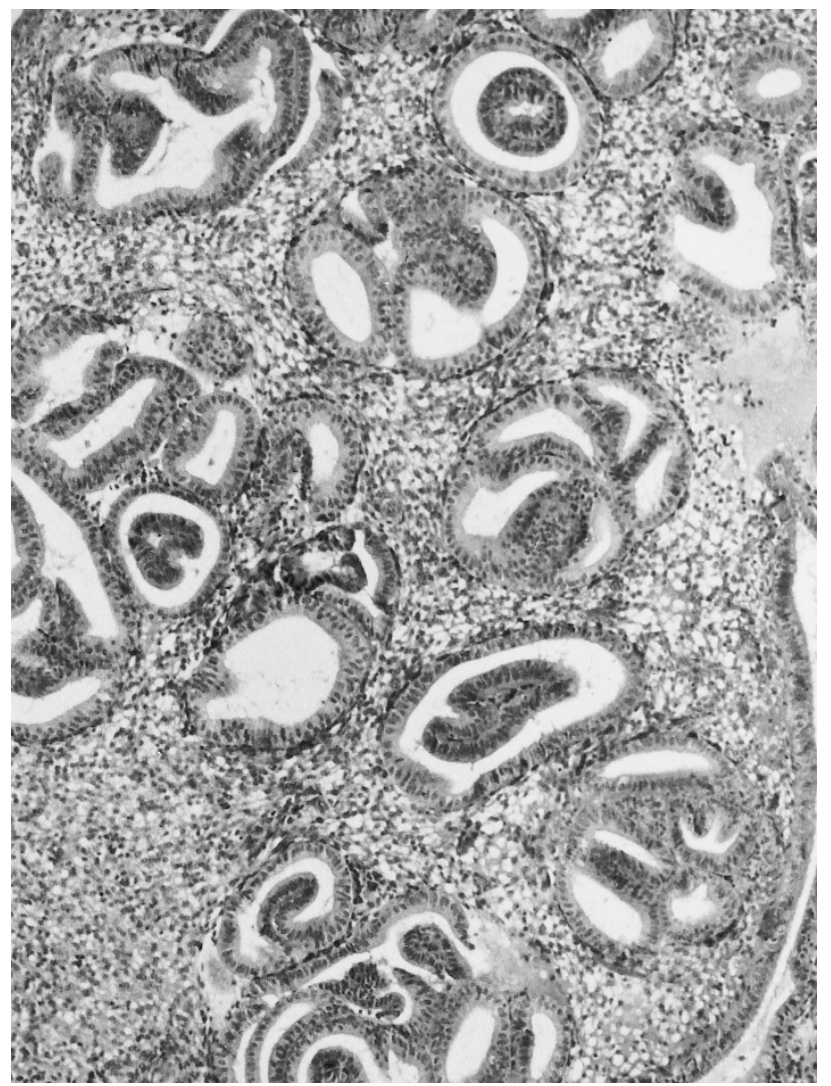

FIGURE 6. Proliferative endometrium, showing extensive

"telescoping" artifact, producing numerous double-barreled lumina, simulating complex hyperplasia. This was a focal finding in what was otherwise typical proliferative phase endometrium.

worth contrasting the putative atypical gland or glands with adjacent hyperplastic glands that are not atypical (20, 24, 25) (Figs. 9 and 10). I find that the presence of a true dichotomy between these two different types of glands is the best way to ensure that diagnosable atypia is present.

In addition to the other forms of hyperplasia and endometrioid adenocarcinoma, as well as the other differential diagnoses mentioned above, atypical hyperplasia involves a new set of differential diagnostic possibilities because of a number of other lesions that mimic cytologic atypia within a hyperplasia. These are all encompassed within the spectrum of lesions classified as epithelial metaplasias and related changes (Table 1). Of the lesions listed in this table, the most important for differential diagnostic purposes are ciliary, eosinophilic, surface syncytial, and papillary changes (3). Squamous metaplasia and morules are also worth noting, because it is sometimes falsely assumed that any lesion with extensive squamous or morular proliferation is necessarily a carcinoma; thus, these changes are more a part of the differential diagnosis with low-grade endometrial adenocarcinoma than with atypical hyperplasia per se.

The main importance of ciliary change (tubal metaplasia) and eosinophilic change is that, by vir- 


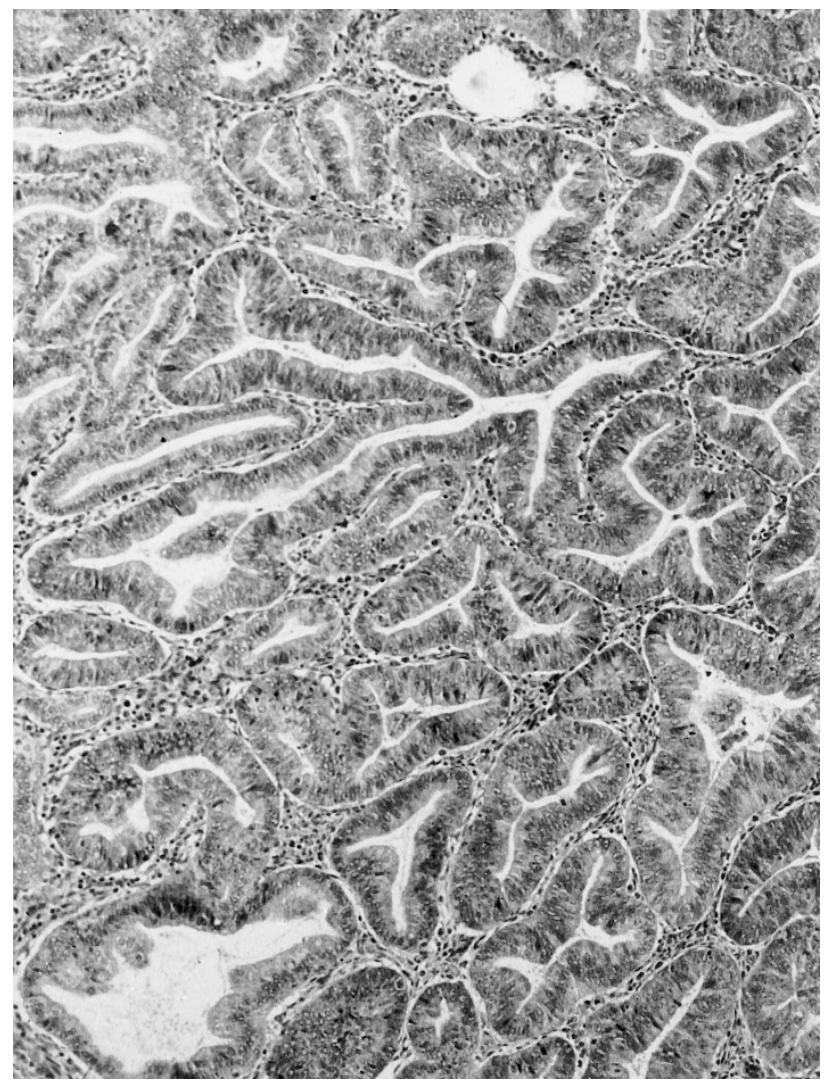

FIGURE 7. Complex hyperplasia. The glands in this field are crowded and architecturally irregular, with angular contours and numerous side buds. Nuclear atypia was lacking at higher power observation.

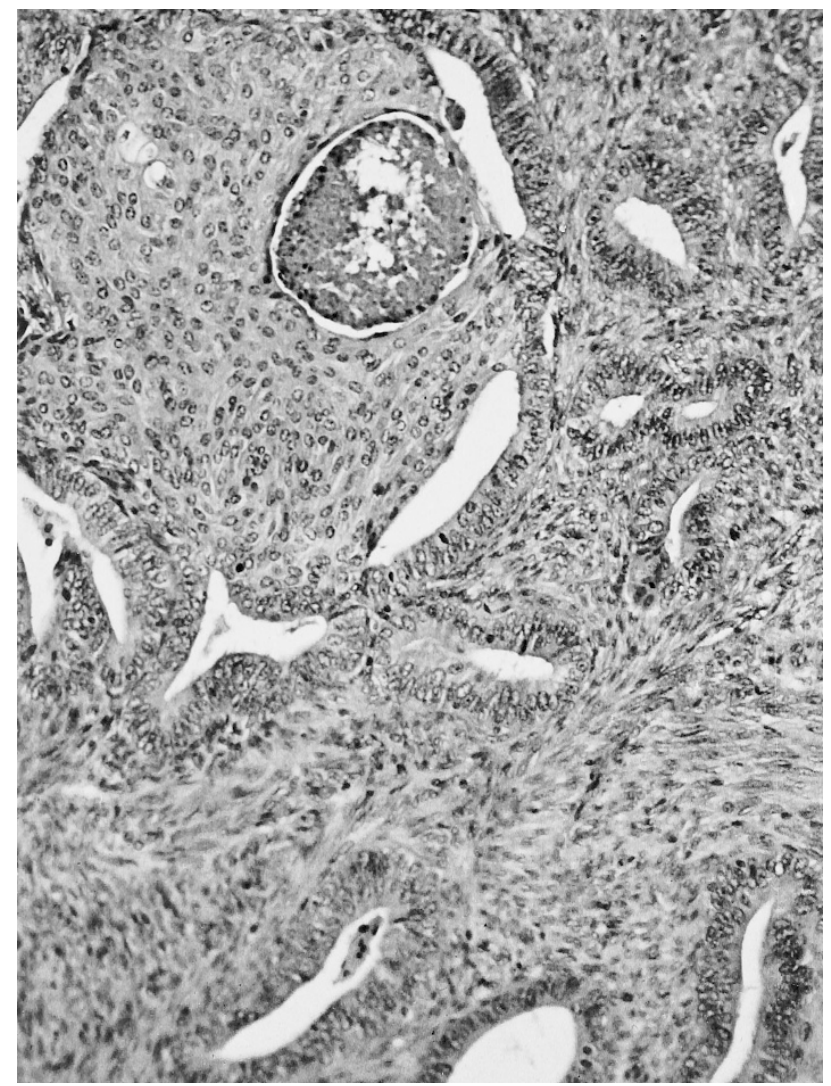

FIGURE 8. Atypical polypoid adenomyoma. Largely unoriented glands are separated by a stroma composed of intersecting and swirling fascicles of smooth muscle. A large squamoid morule with central necrosis is seen in the upper left-hand corner. tue of their eosinophilic appearance at low magnification, they draw attention to glands that may then be confused with those of an atypical hyperplasia. The nuclear features described above for atypical hyperplasia, however, are not seen in either ciliary or eosinophilic change, the nuclei of which should be unstratified and cytologically bland (Fig. 11).

Surface syncytial change and papillary proliferation are two lesions that tend to occur at or near the endometrial surface but frequently extend into superficial glands. They are often seen in the same endometrium and may also be accompanied by one or more of the other metaplastic and related lesions. Syncytial change often resembles microglandular hyperplasia of the endocervix because small glandular lumina or pseudolumina may be formed, which are frequently infiltrated by neutrophils. The nuclei are bland and may show degenerative and pyknotic changes. Cellular stratification and budding may lead to prominent papillarity, but the papillae lack stromal cores (Fig. 12). When fibrovascular stromal cores are present, papillary proliferation is diagnosed. In both of these lesions, by definition, the nuclei are small, uniform, and cytologically bland; therefore, confusion with atypical hyperplasia should be avoided. Furthermore, these two lesions are generally seen at or near the surface of the endometrium and less commonly within the deeper crowded glands of a complex hyperplasia. However, in a biopsy or curettage specimen, it is sometimes difficult to distinguish the superficial from the deep (Fig. 13).

It is also important to realize that the architectural appearance of syncytial and papillary changes may mimic that of serous carcinoma of the endometrium. The latter, however, is a high-grade cancer with marked atypia, necrosis, cellular exfoliation, and prominent mitotic activity. Extremely large eosinophilic nucleoli are usually present within the cells of a serous carcinoma. If a lesion thought to be a metaplastic change shows any significant degree of nuclear atypia, the possibility of serous carcinoma or endometrial intraepithelial carcinoma should be ruled out by an immunostain for p53 protein, which is virtually always diffusely positive in the latter lesions (1).

\section{DIFFERENTIAL DIAGNOSIS OF ENDOMETRIAL HYPERPLASIAS AND LOW-GRADE ENDOMETRIOID ADENOCARCINOMAS}

Having discussed the spectrum of endometrial hyperplasias and their differential diagnosis with 


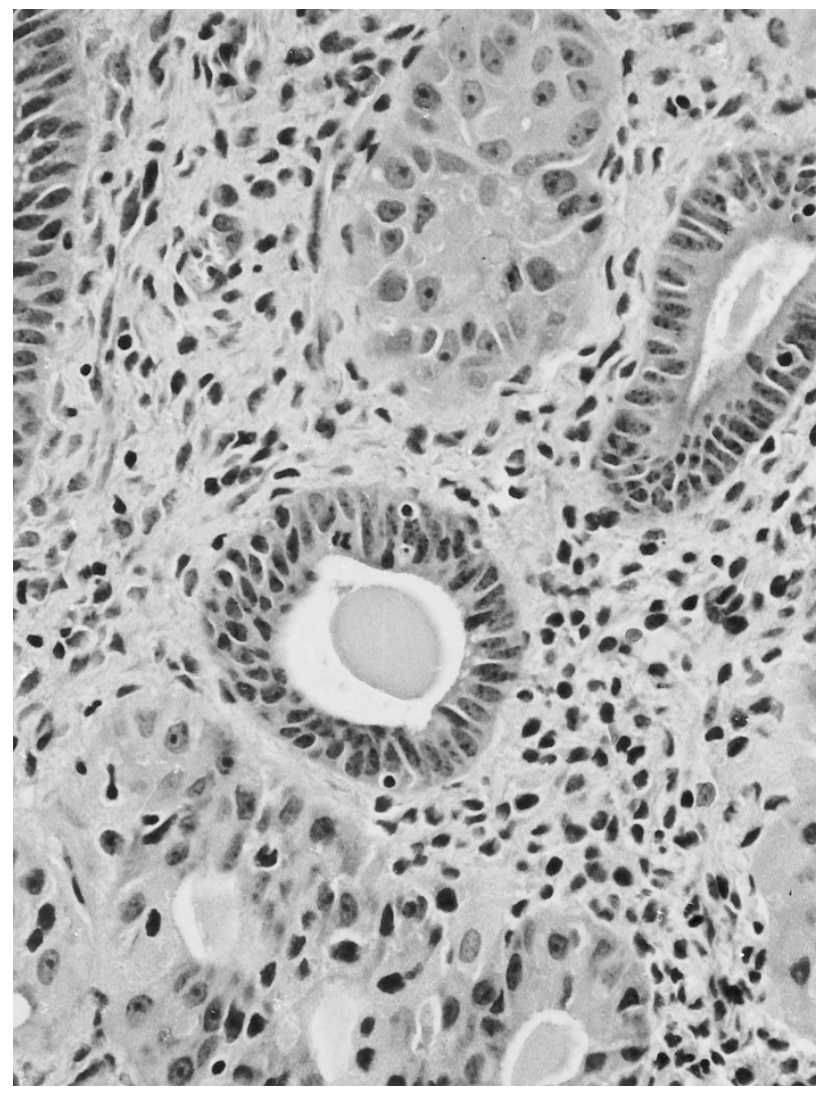

FIGURE 9. Atypical complex hyperplasia. High-power

photomicrograph shows atypical glands with dyspolaric cells containing eosinophilic cytoplasm and enlarged, rounded nuclei with prominent nucleoli. In the center of the figure and at upper right are two hyperplastic but nonatypical glands for comparison.

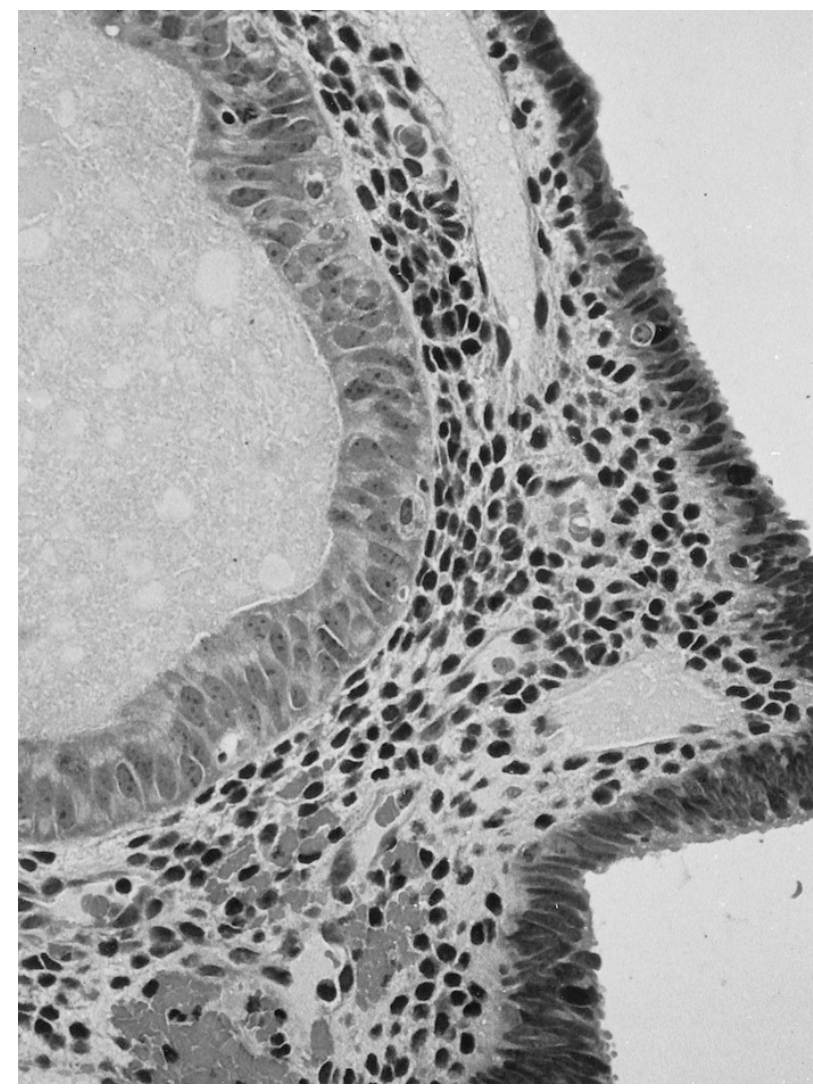

FIGURE 10. Atypical simple hyperplasia. Although the simple versus complex architecture of this illustration and Figure 9 cannot be ascertained from the high-power illustrations used, this figure again contrasts the epithelium of an atypical gland (left) with that of an adjacent hyperplastic gland lacking atypia (right).

TABLE 1. Epithelial Metaplastic and Related Changes

Squamous metaplasia and morules

Mucinous metaplasia (including intestinal)

Ciliary change

Hobnail change

Clear cell change

Eosinophilic cell change (including oncocytic)

Surface syncytial change

Papillary proliferation

Arias-Stella change

nocarcinoma is the presence of myometrial invasion in the subsequent hysterectomy specimen (26-29).

However, even this standard may often prove unreliable for the following reasons: 1) many patients in whom a diagnosis of atypical hyperplasia is made will not undergo a hysterectomy until months or years later, if ever, and various nonsurgical therapeutic measures may have been applied in the interim; 2) a prospective study has never been performed in which the hysterectomy specimens after diagnoses of atypical hyperplasia or well-differentiated adenocarcinoma were subjected to a uniform protocol in terms of fixation, dissection, and histologic examination; thus, reported frequencies of myoinvasion may be underestimates if some of the cases were less than thoroughly studied; 3) it is well-established that a 


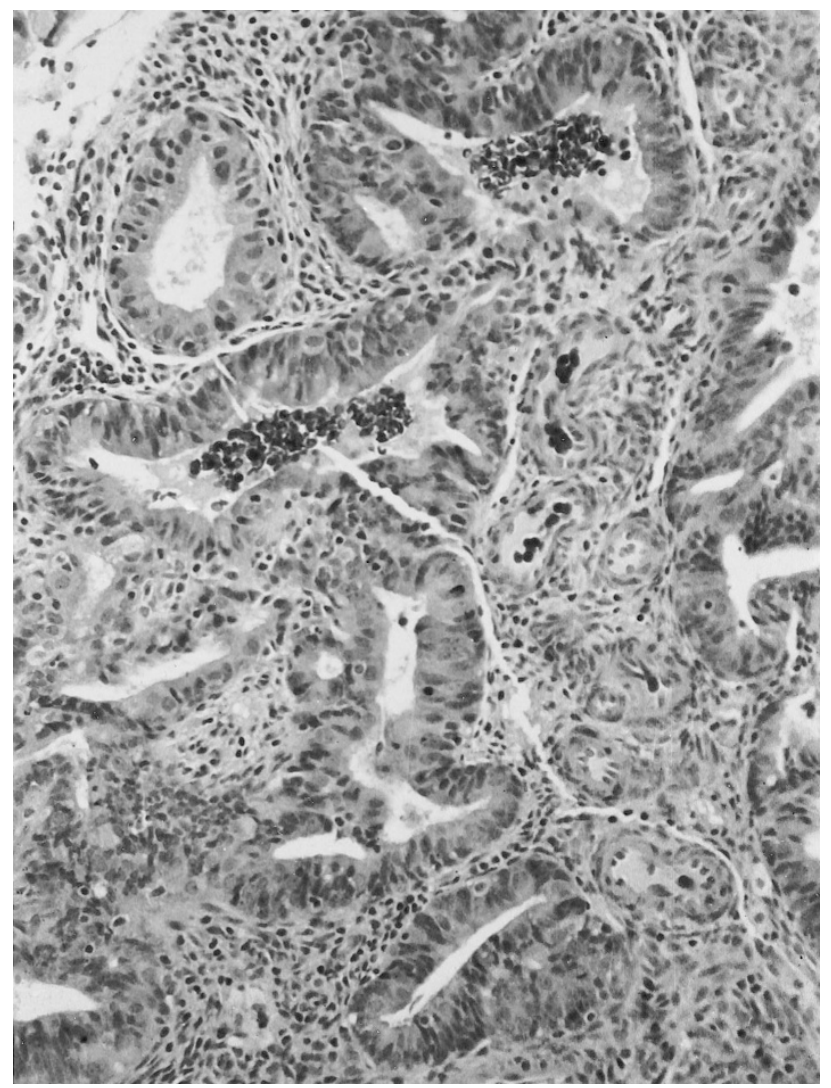

FIGURE 11. Hyperplastic endometrium with ciliary change (tubal metaplasia). Even at this magnification, the resemblance of the lining cells to tubal epithelium is evident. The nuclei lack the features of cytologic atypia seen in Figures 9 and 10.

significant proportion (probably at least $30 \%$ and considerably higher in some series) of well-documented low-grade endometrioid adenocarcinomas of the endometrium will show no myoinvasion at the time of hysterectomy, so the lack of myoinvasion cannot be construed as evidence of an incorrect diagnosis (30); 4) similarly, several studies have indicated that atypical hyperplasia diagnosed at biopsy or curettage will be accompanied in at least $15 \%$ to almost $50 \%$ of immediate hysterectomy specimens by adenocarcinoma, and a proportion of these will be myoinvasive (31); and 5) the determination of myoinvasion is itself subject to considerable observer variation, as shown in one recent study in which $25 \%$ of referred endometrial carcinoma cases diagnosed as myoinvasive were thought to be limited to the endometrium on subsequent review (32). Thus, although the goal of a diagnostic schema to separate endometrial atypical complex hyperplasia and endometrioid adenocarcinoma might be considered the presence of myoinvasion in none of the former and all of the latter, it can safely be stated that this goal will never be achieved. Goals that might be achievable include never having a myoinvasive lesion underdiagnosed as hyperplasia, or never having a hysterectomy performed for a lesion that is not or does not have the potential to be myoinvasive. However, the first of these goals would ob-

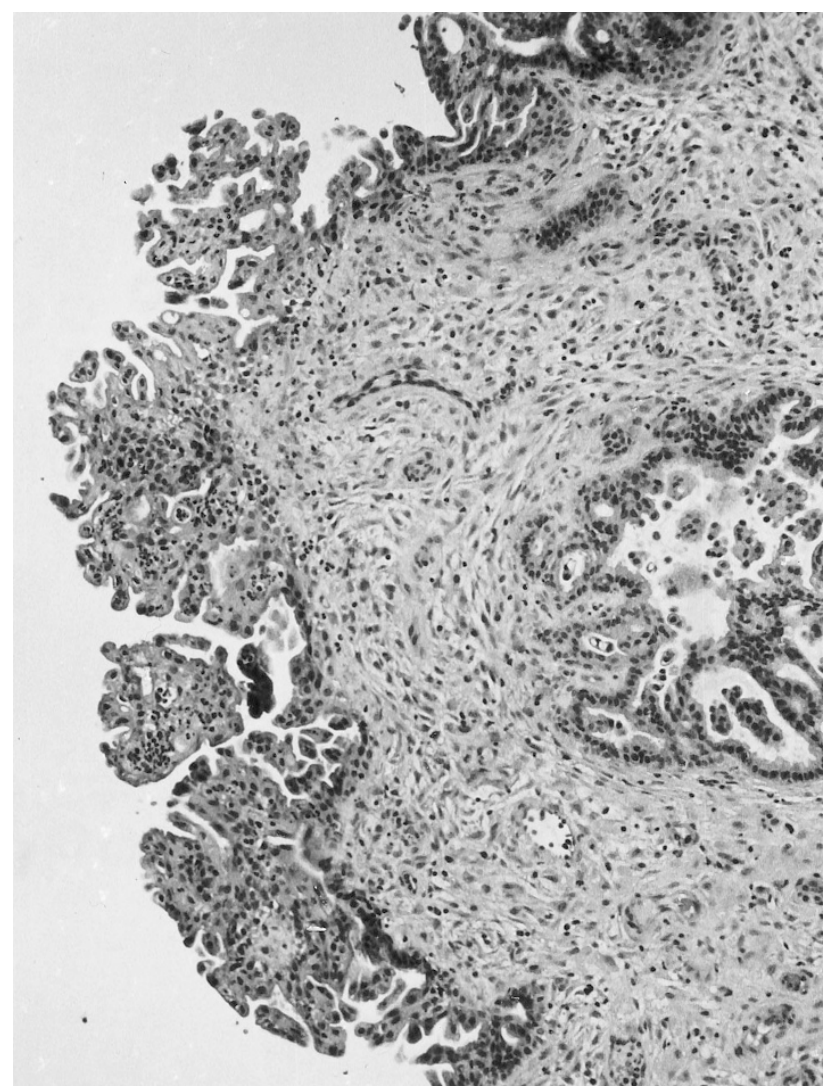

FIGURE 12. Surface syncytial change. In this specimen, it is apparent that the syncytial and papillary proliferation is growing largely on the endometrial surface, with involvement of a superficially located gland. Numerous neutrophils are seen within the microglandular and micropapillary epithelium.

viously demand an unacceptably low threshold for the diagnosis of carcinoma, whereas the second would require an equally unacceptably high threshold. Thus, we probably are safest setting our "cancer thermostat" at an intermediate level and accepting that both underdiagnosis and overdiagnosis of some of these lesions will continue to occur.

Placing these philosophical considerations aside, one can summarize the published studies of differential diagnostic criteria by stating that most of them seem to consider cytologic features little help in the distinction between atypical complex hyperplasia and low-grade endometrioid adenocarcinoma. Some of the atypical hyperplasias are cytologically more malignant in appearance than many low-grade adenocarcinomas. Within the spectrum of low-grade adenocarcinomas, there are many that show prominent nuclear atypia (usually a finding of higher-grade endometrioid and almost all nonendometrioid adenocarcinomas of the endometrium), but at the level of difficult differential diagnosis that we are currently exploring, nuclear atypia is not an important distinguishing feature. The other statement in summation of the published differential diagnostic criteria is that they all rely on features that can be used to determine whether the glands of a proliferating lesion have in- 


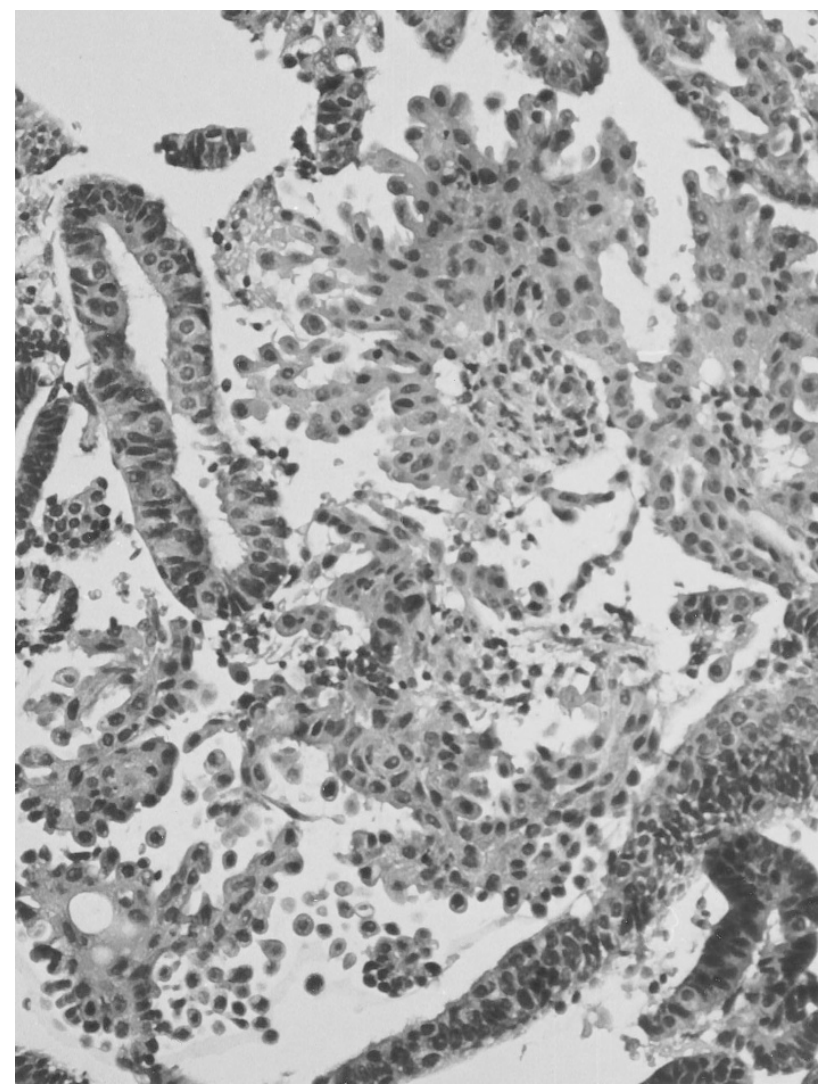

FIGURE 13. Higher-power view of surface syncytial change, in which the orientation of this curettage specimen makes it difficult to appreciate that the syncytial proliferation is on the surface. Note the lack of nuclear atypia in these cells, as well as a gland with ciliary change (tubal metaplasia), illustrating that different patterns of metaplastic and related changes often occur together.

vaded their own stroma. Thus, the "cribriform pattern" and "intraglandular gland cell bridging without stromal support" of Tavassoli and Kraus (28), the "confluent glandular bridges and aggregates of glands lacking intervening stroma" and "branching, complex papillary epithelial-lined processes" of Kurman and Norris (27), and the "confluent complex glands" and "gland-within-gland pattern with papillary infoldings and bridges (complex filigree pattern)" of Hendrickson et al. (26) are, essentially, different ways of saying the same thing. In the recent article of Kendall et al. (20), "glandular confluence" and "stromal alteration" were again found to be the most useful features in a multiobserver diagnostic study of the reproducibility of the diagnosis of atypical hyperplasia versus carcinoma.

For many years, we have argued that these different criteria-which have been argued with great force and occasional rancor in print-are different iterations of the same thing, and we have reduced the diagnostic criteria of stromal invasion (and therefore of adenocarcinoma) to three histopathologic findings, which may be summarized as (1) stromal disappearance, (2) stromal desmoplasia, and (3) stromal necrosis $(24,25)$. Stromal disap- pearance is a summary of what happens in the pattern of invasion that has generally been referred to as confluent, cribriform, or back-to-back. The stroma between adjacent glands essentially disappears so that the basement membranes of the glands are applied directly to one another (Figs. 14 and 15). In the pattern of stromal desmoplasia, the glands are still separated, but rather than by normal endometrial stroma, they are separated by the classic desmoplastic stroma-with its myofibroblasts, edema, inflammatory cells, and myxoid changethat we recognize in adenocarcinomas of many other organs (Fig. 16). Finally, the least common pattern is one in which, at low magnification, endometrial stroma seems to persist between adjacent glands. However, observed at higher magnification, this stroma is actually masses of neutrophils that have replaced the stroma with a necroinflammatory debris (Fig. 17).

These patterns usually coexist and may also coexist with other features of atypical hyperplasia or features that are suggestive but not diagnostic of carcinoma. In the latter category, we would include the presence of stromal foam cells (Fig. 18). Although I am convinced that these are observed far more frequently in carcinomas than in benign processes, they can be observed in the latter, and some authors suggest that they are encountered as fre-

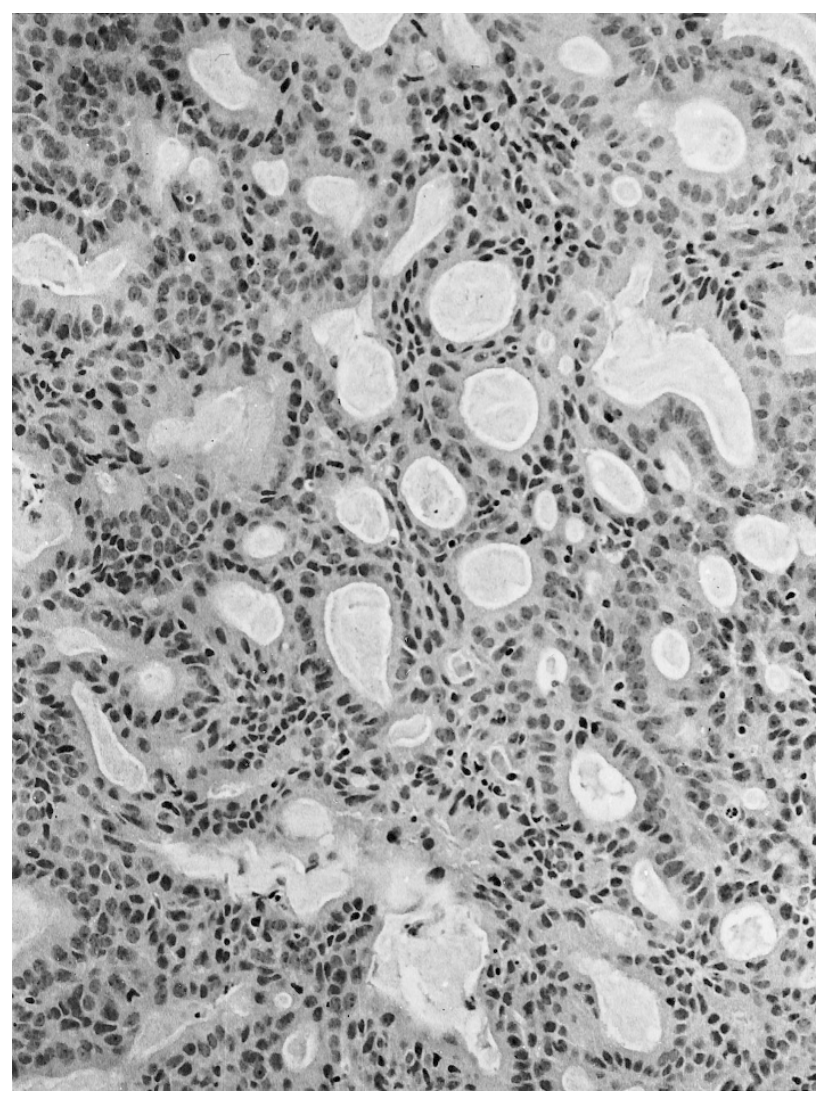

FIGURE 14. Cribriform pattern of well-differentiated endometrioid adenocarcinoma, in which stroma between glands has disappeared as the glands have grown together. 


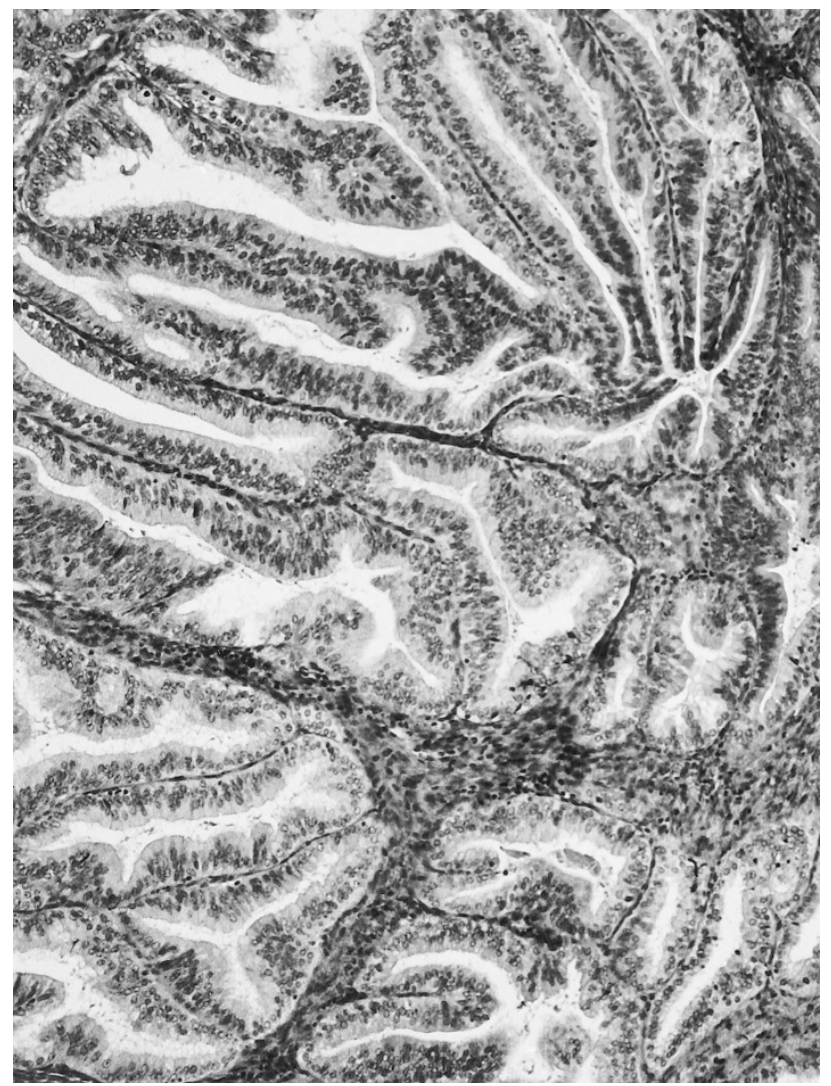

FIGURE 15. Well-differentiated endometrioid adenocarcinoma. Another case in which glands have become confluent by replacing the stroma that originally existed between them in several islands. The growth pattern is somewhat villoglandular.

quently in benign endometria as in malignant ones (33). Because these foam cells are thought to represent altered endometrial stromal cells, it can be argued that stromal cells are thus still present, albeit in an altered state, between the endometrial glands, and thus the foam cell change does not represent true stromal invasion. When I encounter foam cells in a biopsy in which I cannot otherwise diagnose carcinoma, I usually recommend that the patient undergo formal dilatation and curettage, and in most such cases, the diagnosis of carcinoma has then been made on the basis of the criteria provided above. It should also be mentioned that the presence of stromal foam cells is an accurate though infrequent criterion of the endometrial versus endocervical origin of an adenocarcinoma in a biopsy or curettage specimen. The presence of these cells is virtually diagnostic of an endometrial origin of such an adenocarcinoma, but unfortunately, they are found only in approximately $15 \%$ of such cases (34).

Another finding that has been quoted in the literature as either highly suggestive or diagnostic of endometrial carcinoma is a papillary growth pattern (27). Again, I do not consider this pattern particularly convincing, unless it is the classical villoglandular pattern observed in a subset of endometrioid adenocarcino-

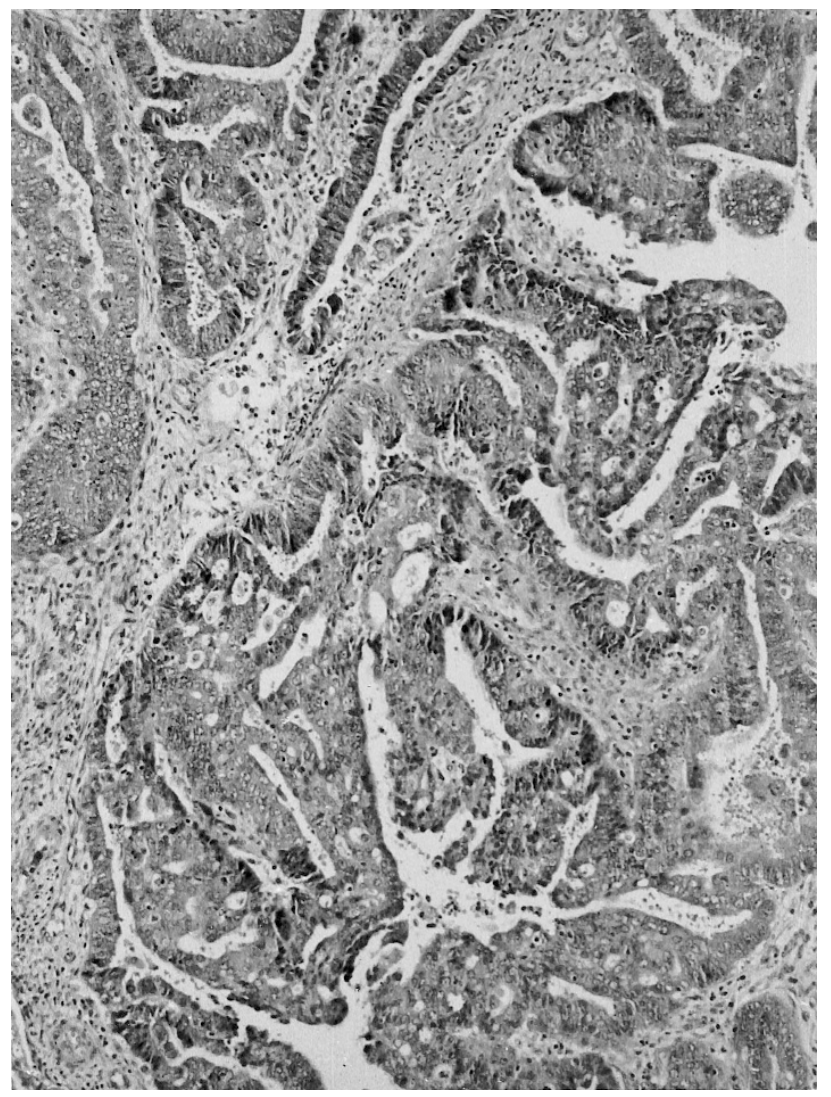

FIGURE 16. Well-differentiated endometrioid adenocarcinoma with prominent desmoplastic stroma separating glands and masses of glands. A confluent pattern is also seen focally.

mas (discussed and illustrated in a later section) or the papillary pattern observed in some nonendometrioid cancers, particularly those of serous and clear cell types. Particularly with the nonendometrioid papillary carcinomas, there will be little tendency for confusion with hyperplasia, so the papillary nature of the tumors is not pertinent to this discussion. The papillary changes that are included among the metaplastic and related lesions (see above) are, however, common in benign endometria; thus, a blanket qualification of papillary change-even when extensive-as indicative of carcinoma is not warranted.

Similarly, extensive squamous growth, which has been cited by Kurman and Norris (27) as indicative of carcinoma, is helpful only if the squamous elements are obviously malignant. When they are, the glandular component of these tumors is usually high grade and unlikely to be confused with hyperplasia, whereas benign squamous metaplasia and its morular variant (as mentioned above) are seen in numerous hyperplastic and other benign endometria.

\section{RISK FOR "PROGRESSION" OF ENDOMETRIAL HYPERPLASIAS}

In addition to the problems raised by the differential diagnosis between endometrial hyperplasia 


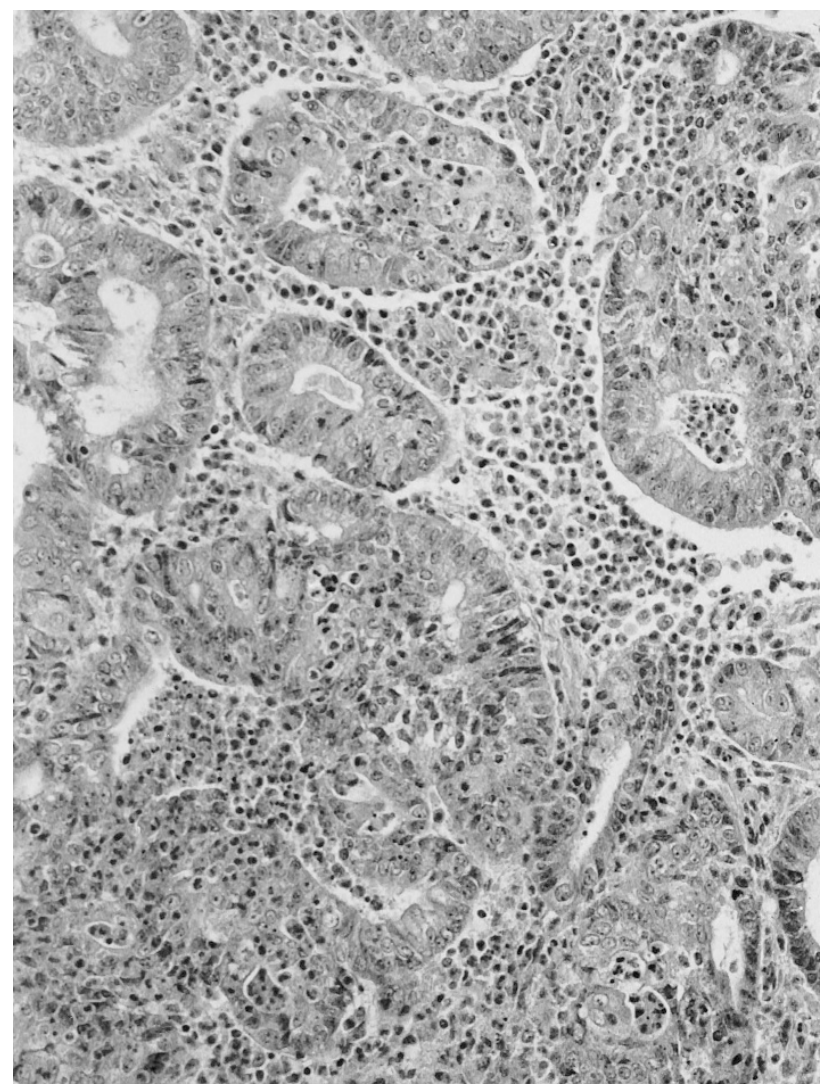

FIGURE 17. Well-differentiated endometrioid adenocarcinoma with malignant glands separated by masses of neutrophils (stromal necrosis)

and carcinoma, there are other relationships between these two entities that should be considered. Primary among them is the risk of progression of an untreated hyperplasia or atypical hyperplasia to adenocarcinoma. Numerous studies have investigated this relationship for at least 5 decades (35-37), but relatively few of these have been prospective studies in which women with biopsy diagnoses of various forms of endometrial hyperplasia have been followed for at least several years to determine the eventual outcome of the disease. It is often difficult to make much sense even of these studies, both because of changing terminology over the years and because women with hyperplasia have often received various forms of nonsurgical therapy-primarily hormonal, but in many cases, radiation therapy-before eventually undergoing hysterectomy or another curettage in which a subsequent diagnosis could be made. Despite these variations in diagnostic criteria, terminology, and follow-up conditions in different studies, there has nevertheless developed a consensus in recent years that certain types of endometrial hyperplasia-particularly those with cytologic atypia, now classified as atypical hyperplasia-represent a much greater risk for progression than do those hyperplasias without cytologic atypia $(38,39)$.

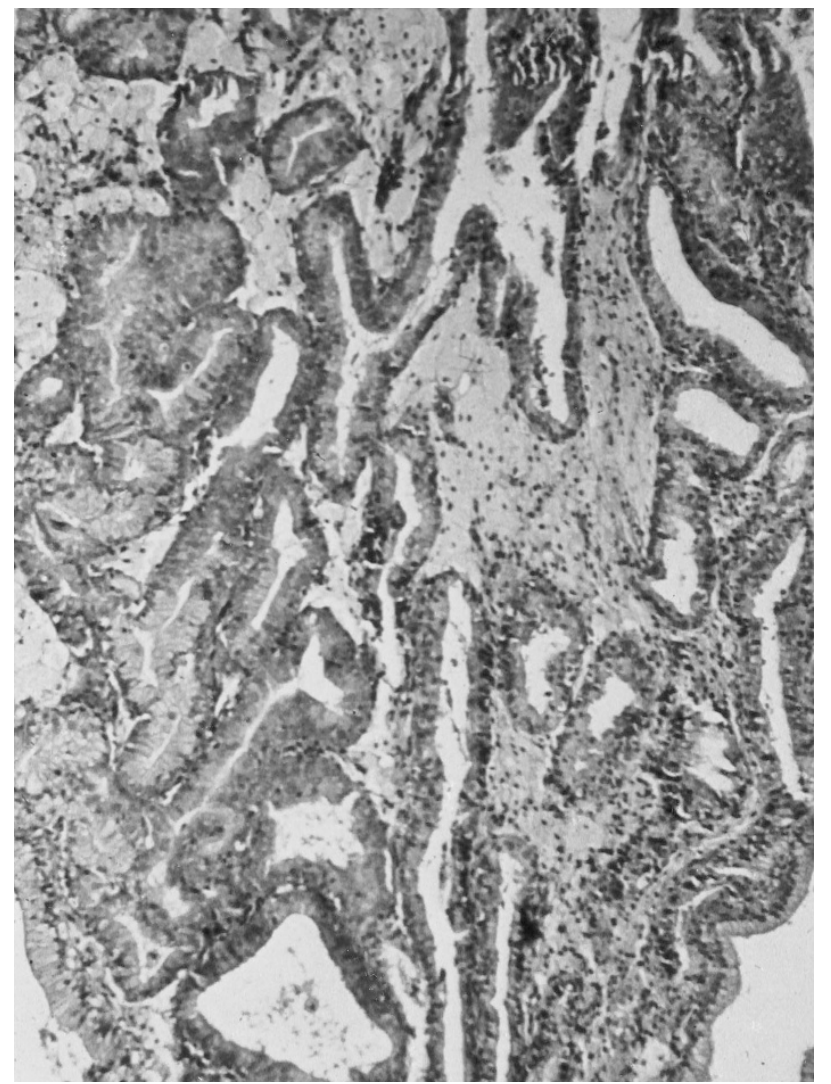

FIGURE 18. Well-differentiated adenocarcinoma in which the intervening stroma between glands has been converted to lipid-laden foam cells. Elsewhere in the specimen, a more typical desmoplastic stroma was present. Note that some of the malignant glands in this field reveal mucinous degeneration, but the foam cell change is a good indicator that the tumor is primary in the endometrium rather than in the endocervix.

A few points should be made about the data generated from the prospective studies, however. First, there is considerable variation in the actual risk quoted for each of the types of hyperplasia. Thus, in the four series that I have chosen to summarize in Table 2, the quoted risks for progression of simple hyperplasia without atypia vary from 0 to $10 \%$; for complex hyperplasia without atypia from 3 to $22 \%$; for atypical simple hyperplasia, there is a degree of stability with quoted figures of 7 and $8 \%$ (and two series not quoting this entity at all); and for atypical complex hyperplasia, the risk for progression varies from 29 to $100 \%$ (39-42). If all of the cases in all of the series are added up and all of those that progressed to carcinoma are added as well, the mean risks for progression are $4.3 \%$ for simple hyperplasia, $16.1 \%$ for complex hyperplasia, $7.4 \%$ for atypical simple hyperplasia, and $47.0 \%$ for atypical complex hyperplasia. Thus, at least in these four series, there may actually be a greater risk associated with the complex architectural pattern than with cytologic atypia. It should also be noted that atypical simple hyperplasia is the least common type among the four patterns of hyperplasia, 


\begin{tabular}{|c|c|c|c|c|c|}
\hline & Type & $\begin{array}{l}\text { No. of } \\
\text { Cases }\end{array}$ & $\begin{array}{c}\text { Persisted } \\
(\%)\end{array}$ & $\begin{array}{c}\text { Progressed } \\
(\%)\end{array}$ & $\begin{array}{c}\text { Follow-Up } \\
(\mathrm{Yr})\end{array}$ \\
\hline \multirow[t]{4}{*}{ Sherman and Brown (1979) } & Cystic & 52 & 6 & 10 & $2-18$ \\
\hline & Adenomatous & 113 & 49 & 22 & \\
\hline & Atypical & 91 & 38 & 57 & \\
\hline & CIS & 12 & 8 & 58 & \\
\hline \multirow[t]{4}{*}{ Kurman et al. (1985) } & Simple & 93 & 19 & 1 & $1-26.7$ \\
\hline & Complex & 29 & 17 & 3 & \\
\hline & Simple atypical & 13 & 23 & 8 & \\
\hline & Complex atypical & 35 & 24 & 29 & \\
\hline \multirow[t]{3}{*}{ Huang et al. (1988) } & Cystic & 11 & 36 & 9 & $1-13$ \\
\hline & Adenomatous & 45 & 60 & 9 & \\
\hline & Atypical adenomatous & 2 & 0 & 100 & \\
\hline \multirow[t]{4}{*}{ Baak et al. (1992) } & Simple & 8 & - & 0 & $0.5-5+$ \\
\hline & Complex & 6 & - & 17 & \\
\hline & Simple atypical & 14 & - & 7 & \\
\hline & Complex atypical & 11 & - & 45 & \\
\hline
\end{tabular}

accounting for only 27 cases (approximately 5\%) of the total 535 cases summarized in these four series.

This hazy picture of the progression risk of endometrial hyperplasia to carcinoma becomes even more confusing when these data are compared with those reported for the presence of endometrial carcinoma in uteri obtained at hysterectomy performed immediately (within 1 month) after the biopsy or curettage diagnosis of atypical endometrial hyperplasia. As summarized by Hunter et al. (31), this ranges from 15 to $43 \%$, with a total of 103 cases (23\%) in 444 reported in six series in the literature, including their own. As many of these uteri were not sampled extensively in a prospective fashion, the real figure may be considerably higher. Nevertheless, it does not differ significantly from the $29 \%$ progression rate reported by Kurman et al. (39) for atypical complex hyperplasia in patients followed for as many as 26.7 years and differs only in degree from the $47 \%$ rate that is a summary of the four series summarized above. Thus serious consideration must be given to the possibility that the carcinomas found in patients 10,15 , or more years after the diagnosis of atypical hyperplasia may represent carcinomas that were initially present in the uterus and persisted rather than progressed in the intervening time.

It should be noted that this possible behavior is consistent with what we know of the natural history of those endometrial carcinomas associated with endometrial hyperplasia. These tumors, now generally referred to as Type 1 endometrial carcinomas, tend to occur in nulliparous, obese, hypertensive, and/or diabetic women, frequently with ovarian hormone-producing lesions, or in women who have received exogenous estrogens, and are generally low grade and low stage, slowly progressive, and associated with a favorable prognosis. Type 2 endometrial carcinomas, on the other hand, occur in women who are not constitutionally predisposed in any known way, and usually occur on a background of nonhyperplastic, often atrophic endometrium, and these carcinomas tend to be high grade, frequently of nonendometrioid type, often present at a high clinical stage, and have a highly unfavorable prognosis $(1,3,43-47)$. These clinical and pathologic differences, as well as their implications for the pathogenesis of the two different types of carcinoma, are discussed by Sherman (1) in much greater detail. The implication here, however, is that we do not know how long it takes for hyperplasias to progress to carcinomas, and it is possible that the so-called progression represents persistence of coexisting lesions in many cases.

\section{SUBTYPES OF ENDOMETRIOID ADENOCARCINOMA}

There are relatively few major types of carcinoma of the endometrium, and the nonendometrioid types are discussed by Sherman (1). This discussion therefore is limited to a brief mention of the subtypes of endometrioid adenocarcinoma currently recognized and some guidelines on histopathologic grading.

In the ISGP, FIGO, and WHO classification of endometrial adenocarcinoma, the listed subtypes under the "endometrioid" heading are limited to adenocarcinoma and its secretory and ciliated cell variants and adenocarcinoma with squamous differentiation, further subdivided into adenocarcinoma with squamous metaplasia (adenoacanthoma) and adenosquamous carcinoma (3). Endometrioid adenocarcinoma in its well-differentiated form, type otherwise unspecified, is the tumor that has already been discussed and illustrated in the discussion on differential diagnosis from atypical complex hyperplasia. The secretory and ciliated cell variants both are rare and well differentiated by definition. Both of these tumors are composed almost exclusively of glands lined by cells with relatively little nuclear atypia. In the secretory variant, 
the glands most resemble those of normal early secretory endometrium. These tumors are rare in pure form but may be seen frequently as foci within other endometrioid carcinomas. They seem to be associated with a favorable prognosis (48).

The ciliated cell variant comprises neoplastic glands composed predominantly or exclusively of ciliated cells. The differential diagnosis is with benign ciliary change, and as with other endometrial carcinomas, the distinction is made by the demonstration of stromal invasion in ciliated cell adenocarcinoma. As with secretory carcinoma, the outcome of the few cases reported has been favorable $(49,50)$.

Unlike the two variants mentioned above, adenocarcinoma with squamous differentiation is a common lesion, comprising up to $50 \%$ of endometrial carcinomas in some series. These tumors were originally thought to be rare, characterized by benign squamous metaplasia within an adenocarcinoma and associated with a favorable prognosis (51). They subsequently became recognized as common and were eventually separated into adenocarcinomas with benign- and malignant-looking squamous components, the former called adenocarcinoma with squamous metaplasia or adenoacanthoma and the latter called mixed adenosquamous carcinoma $(52,53)$. Because the natural history depends more on the glandular than the squamous component, the most recent stage in the consideration of these tumors is that they may all be combined as adenocarcinomas with squamous differentiation, with the decision of whether to subdivide them left to the individual pathologist (54).

In all of these lesions, by definition, a squamous component coexists with the malignant glandular element. In adenocarcinomas with squamous metaplasia, the squamous component consists of squamous or morular elements that appear histologically benign and generally grow on the surface of the tumor, within gland lumina, or in both sites (Fig. 19). The glandular component is characteristically low grade, and the prognosis is at least as favorable as that for other low-grade endometrioid adenocarcinomas and probably even slightly better. In adenosquamous carcinoma, the squamous component is, by definition, cytologically malignant and is usually also recognizable as malignant by its tendency to invade out from the glands into the stroma (Fig. 20). In these tumors, the glandular elements are usually moderately or poorly differentiated. The prognosis of adenosquamous carcinoma seems to be exactly the same as that of pure adenocarcinoma of similar histopathologic grade; thus, the squamous element is not thought to influence the prognosis either favorably or unfavorably in these cases (54).

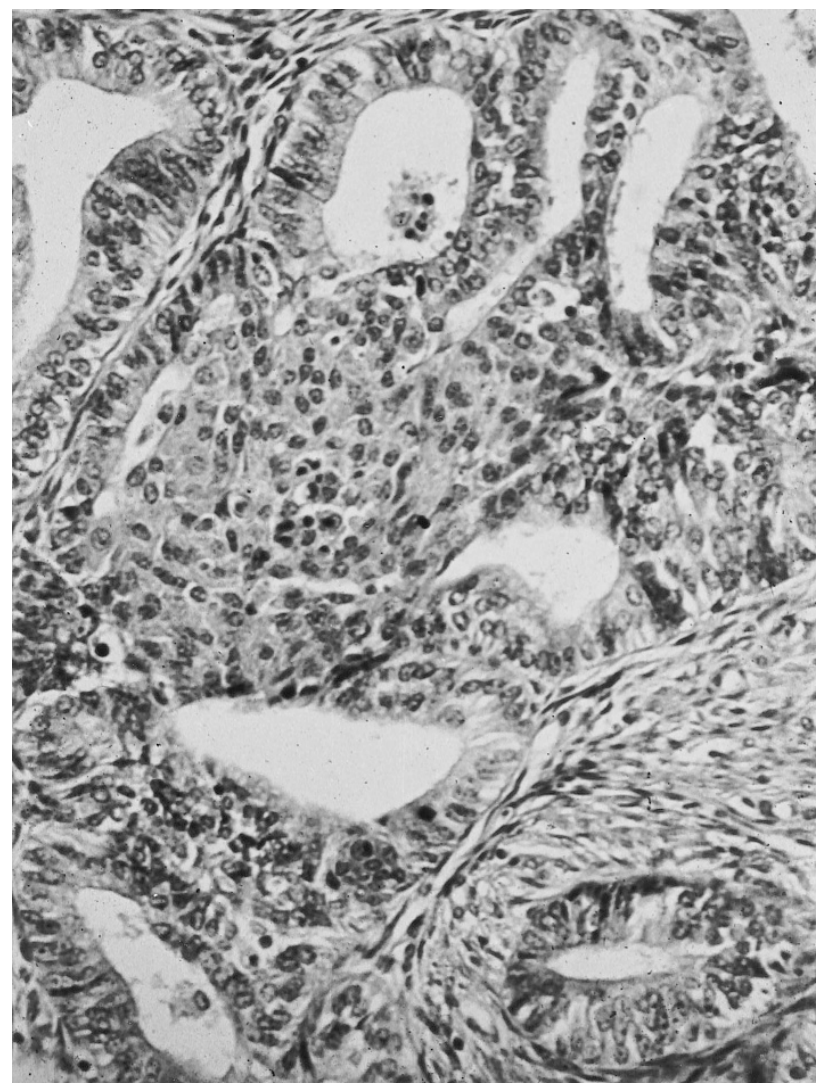

FIGURE 19. Endometrioid adenocarcinoma with squamous differentiation, adenoacanthoma type. There is a squamoid morule that appears cytologically benign in the center of the photomicrograph. Note the confluent nature of the surrounding glands and the desmoplastic stroma, indicating that this is indeed a carcinoma. The glandular component throughout this tumor, as in this field, was well differentiated (FIGO Grade 1).

It is frequently difficult to distinguish the undifferentiated portion of a high-grade adenocarcinoma from poorly differentiated squamous elements (Fig. 21). Although the presence of the latter does not influence the prognosis, it is important to distinguish squamous from glandular components, because only the latter are graded. The general rule is that, unless squamous differentiation can be demonstrated clearly, the diagnosis of adenosquamous carcinoma should not be made. The criteria for squamous differentiation in the ISGP/FIGO/ WHO classification are as follows: (1) keratinization demonstrated with standard staining techniques, (2) intercellular bridges, or (3) three or more of the following four criteria: (a) sheet-like growth without gland formation or palisading, (b) sharp cell margins, (c) eosinophilic and thick or glassy cytoplasm, and (d) a decreased nuclear:cytoplasmic ratio (compared with foci elsewhere in the same tumor) (3).

A final variant to discuss, which is not included in the classification mentioned above, is the villoglandular pattern of endometrioid adenocarcinoma (55-57). Papillary structures may be seen in many endometrioid adenocarcinomas of predominantly 


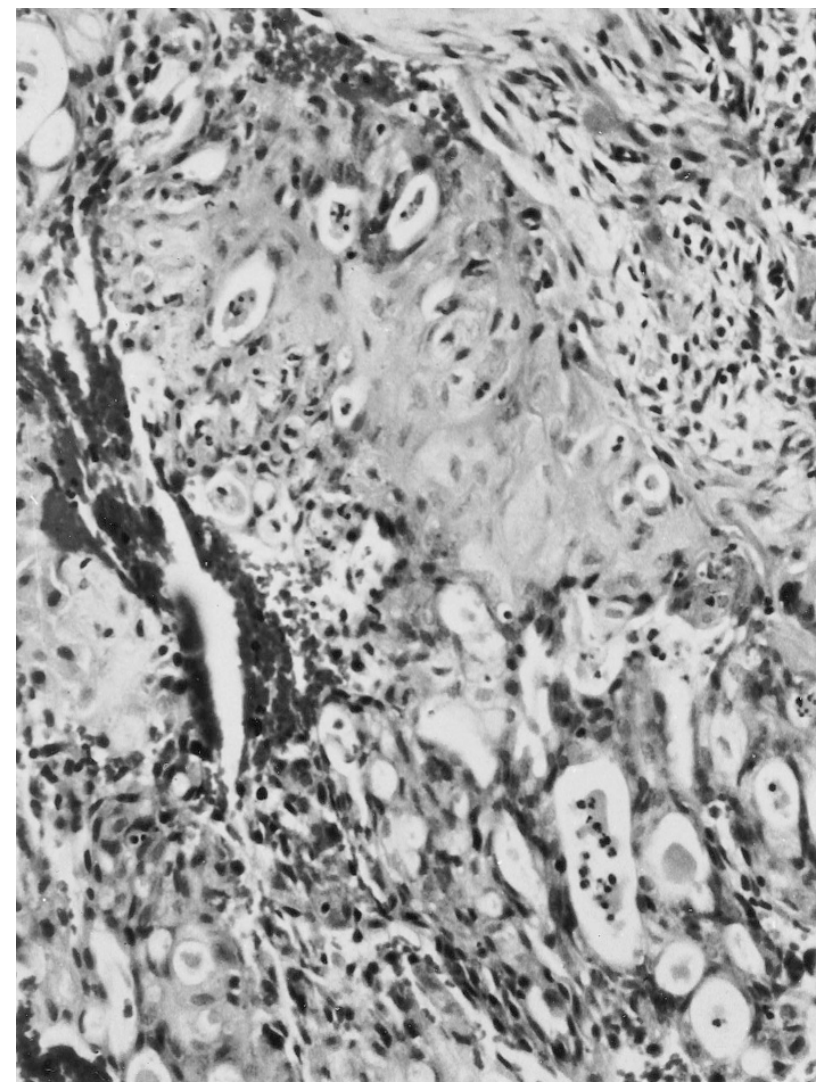

FIGURE 20. Endometrioid adenocarcinoma with squamous differentiation, mixed adenosquamous carcinoma type. In this tumor, the squamous epithelium present appears cytologically malignant and is in direct apposition to the adjacent desmoplastic stroma. Many of the apparent glands in this figure actually represent microcystic foci of necrosis within the squamous or poorly differentiated glandular component.

glandular type, but when they become the dominant pattern, the tumor is known as villoglandular or papillary. It is important to distinguish these tumors from serous or clear cell adenocarcinomas growing in a papillary pattern, because the latter two tumors are considered Type 2 nonendometrioid carcinomas with a poor prognosis and are often selected for adjuvant chemotherapy and/or radiotherapy, even in the absence of myoinvasion at hysterectomy (58). The papillary or villoglandular variant of endometrioid adenocarcinoma, however, is usually well differentiated and is treated like other endometrioid adenocarcinomas. The main differential diagnostic feature is that the cells of the latter tumor are similar to those of the classic glandular endometrioid pattern, tending to have a uniform columnar morphology with their relatively bland nuclei arranged perpendicular to the basement membrane. The papillary structures bearing these tumor cells are generally fairly simple and thin, without the broad fibrovascular cores of serous carcinoma, and the cells do not show the prominent exfoliation of serous carcinoma. The nuclei of both serous and clear cell adenocarcinomas

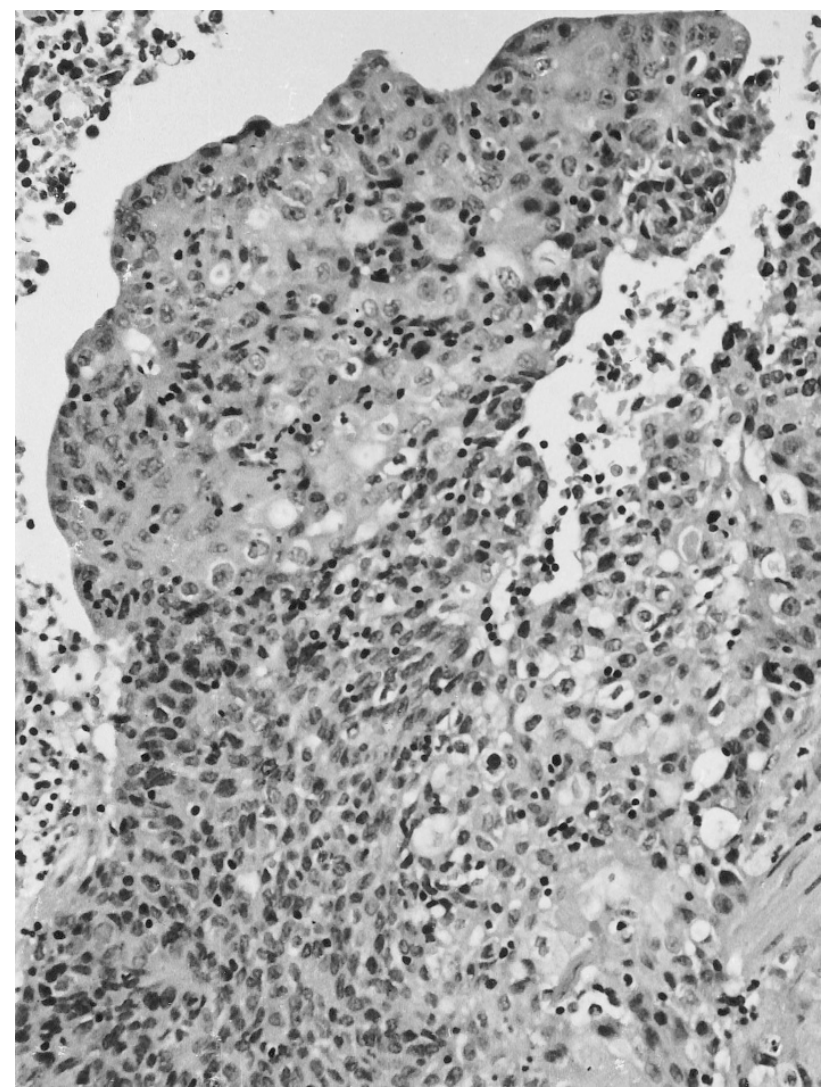

FIGURE 21. High-grade endometrioid adenocarcinoma with squamous differentiation, mixed adenosquamous carcinoma type. Distinction between the solid adenocarcinomatous component seen in the lower left and the malignant squamous elements seen at the top and right is difficult, but the squamous components show sheet-like growth, sharp cell margins, eosinophilic and glassy cytoplasm, and increased amounts of cytoplasm (thus, a lower nuclear:cytoplasmic ratio) compared with the malignant glandular component. In this field, only the glandular component would be graded, and this would be considered FIGO Grade 3 .

tend to be more rounded, larger, and highly atypical, so high power microscopy will usually resolve the issue of whether a papillary endometrial neoplasm is of endometrioid or nonendometrioid type. This differential diagnosis is discussed and illustrated in more detail by Sherman (1). The clear and hobnail cell types of clear cell adenocarcinoma are also characteristic.

It should be noted that endometrioid and nonendometrioid patterns may coexist in the same carcinoma, and the diagnosis of mixed carcinoma is made if the less prevalent type comprises $10 \%$ or more of the total volume of the tumor, as estimated from the examination of multiple sections (3). The types of tumor encountered and their relative proportions should be specified in the pathology report. The prognostic implications of mixed carcinomas in which the subordinate type is less favorable have thus far been poorly characterized, but it is assumed that a serous component comprising more than $25 \%$ of total tumor volume should lead to treatment of the tumor as a serous carcinoma (59). 


\section{GRADING OF ENDOMETRIOID ADENOCARCINOMAS}

Part of the importance of the distinction between endometrioid and nonendometrioid carcinomas is the dictum that only endometrioid carcinomas are graded architecturally, with serous and clear cell adenocarcinomas being considered prognostically unfavorable, by definition. Mucinous adenocarcinoma is fairly uncommon and is almost always well differentiated. Endometrioid adenocarcinomas of the endometrium, however, range from very welldifferentiated to almost totally undifferentiated and indeed probably merge at the higher end of that spectrum with tumors classified as undifferentiated carcinoma.

It is important to remember that only the glandular (or villoglandular) component of an endometrioid adenocarcinoma with squamous differentiation is graded. Thus, as discussed above, it is essential to distinguish the solid component of such a tumor as squamous or glandular, as only the latter is considered in the grade. Grading of this glandular component is predominantly architectural, and in general terms, as the cells diverge from a glandular or papillary pattern to form solid sheets of tumor cells, the tumor is considered more poorly differentiated. In Grade 1 adenocarcinoma, $5 \%$ or less of the tumor grows in a nonsquamous, nonmorular solid growth pattern; in Grade 2, 6 to $50 \%$ of the tumor has such a solid pattern, and more than $50 \%$ of a nonsquamous, nonmorular solid growth pattern characterizes a tumor as Grade 3 (3). It is said that "notable nuclear atypia, inappropriate for the architectural grade, raises the grade of a Grade 1 or Grade 2 tumor by one," but Zaino et al. (60) have shown that only extremely marked atypia should be used to override the architectural grade, and a further caveat should be added that tumors that appear predominantly glandular or villoglandular but have large, bizarre nuclei are often serous carcinomas in which the characteristic papillary architecture is absent (Fig. 22). We have found that such tumors are frequently immunoreactive for p53 protein product, further suggesting their serous rather than endometrioid differentiation.

Although various other grading schemata have been suggested for endometrioid adenocarcinomas $(61,62)$, the almost universally accepted one discussed previously has been shown to be reproducible and an effective indicator of prognosis in many reported series (63-65). Indeed, the treatment of an endometrioid adenocarcinoma of the endometrium will generally depend on the pathologist's intraoperative or postoperative assessment of tumor grade and extent of myoinvasion $(58,66$, $67)$.

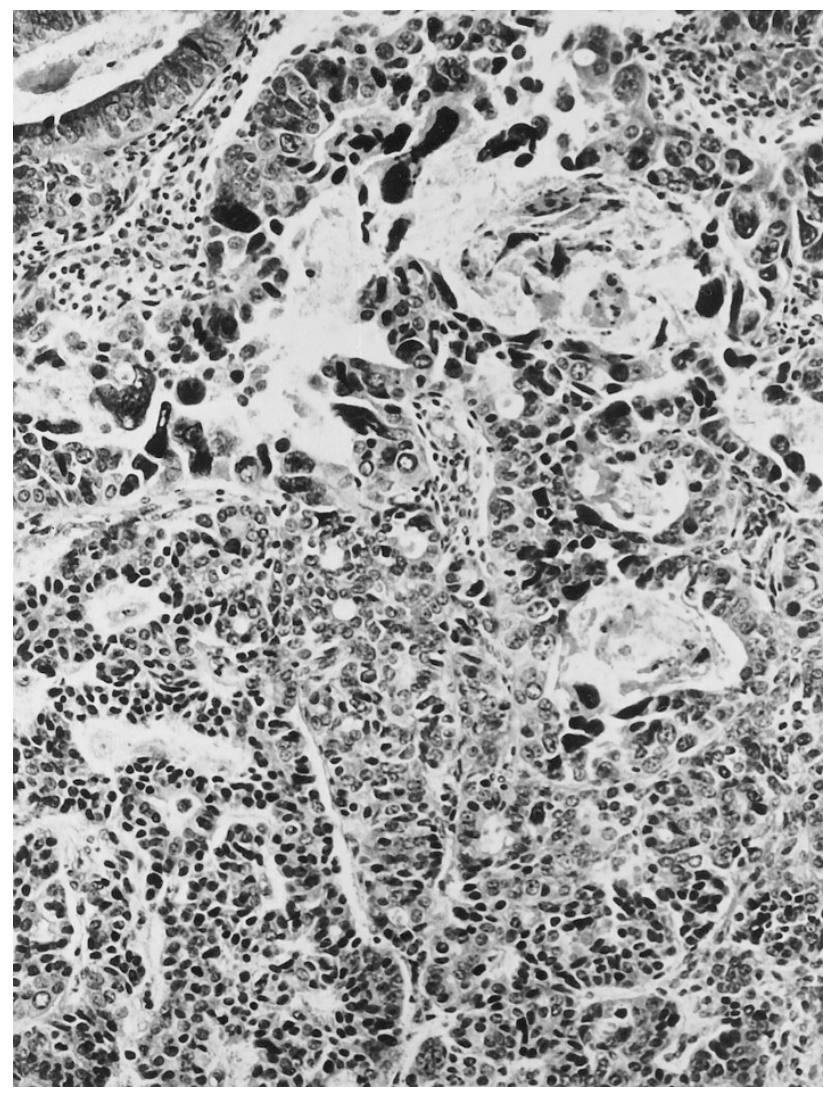

FIGURE 22. Mixed glandular and solid (FIGO Grade 2), apparently endometrioid adenocarcinoma with foci (upper half) of large, bizarre nuclei. Rather than just upgrading this tumor to Grade 3, consideration should be given to the possibility that this represents a serous carcinoma with a predominantly nonpapillary architecture.

\section{ASSESSMENT OF MYOMETRIAL INVASION BY ENDOMETRIAL CARCINOMA}

The assessment of myoinvasion in a hysterectomy specimen would seem to be a relatively simple determination, and it has been quoted as the standard for the diagnosis of endometrial carcinoma in biopsy or curettage specimens (26-29). It also is used as a basis for the decision of whether to add adjuvant radiotherapy or chemotherapy after a hysterectomy and whether to perform lymph node dissections as part of a hysterectomy for endometrial carcinoma (the assessment of myoinvasion is made intraoperatively on a hysterectomy specimen in this situation) $(58,66,67)$. However, in my experience, myoinvasion is frequently overdiagnosed in routine practice, and this impression was recently confirmed by the study of Jacques et al. (32), in which myoinvasion diagnosed by a referring pathologist was denied on review in $25 \%$ of referred hysterectomy specimens with endometrial carcinoma, making this the most frequently detected diagnostic error in this series. There was disagreement between the referring pathologist and the reviewing pathologist in an additional $6.5 \%$ of cases concerning the level of myoinvasion. It is notable 
that there was not a single case in which the referring pathologist failed to diagnose myoinvasion that was found by the reviewers.

The key to this problem is the frequent failure to recognize that the normal endomyometrial junction is often not a straight line, but rather a series of hills and valleys with endometrium dipping down as shorter and longer tongues into the myometrium. Thus, when an endometrium becomes malignant, the carcinoma can also dip into these tongues without raising the spectre of superficial myometrial invasion, which is so frequently overdiagnosed. Furthermore, as an extension of this concept, because adenomyosis is actually a diverticulosis of endometrium deep into the myometrium, carcinoma can also extend deeply in adenomyotic foci without truly invading the myometrium (68). This is an important distinction to make, because none of the reported cases of endometrial carcinoma extending into the myometrium solely within adenomyosis has been known to metastasize, whereas true myoinvasion is frequently associated with distant spread $(69,70)$. Some of the clues for the pathologist in distinguishing extension into adenomyosis from true myoinvasion (Figs. 23

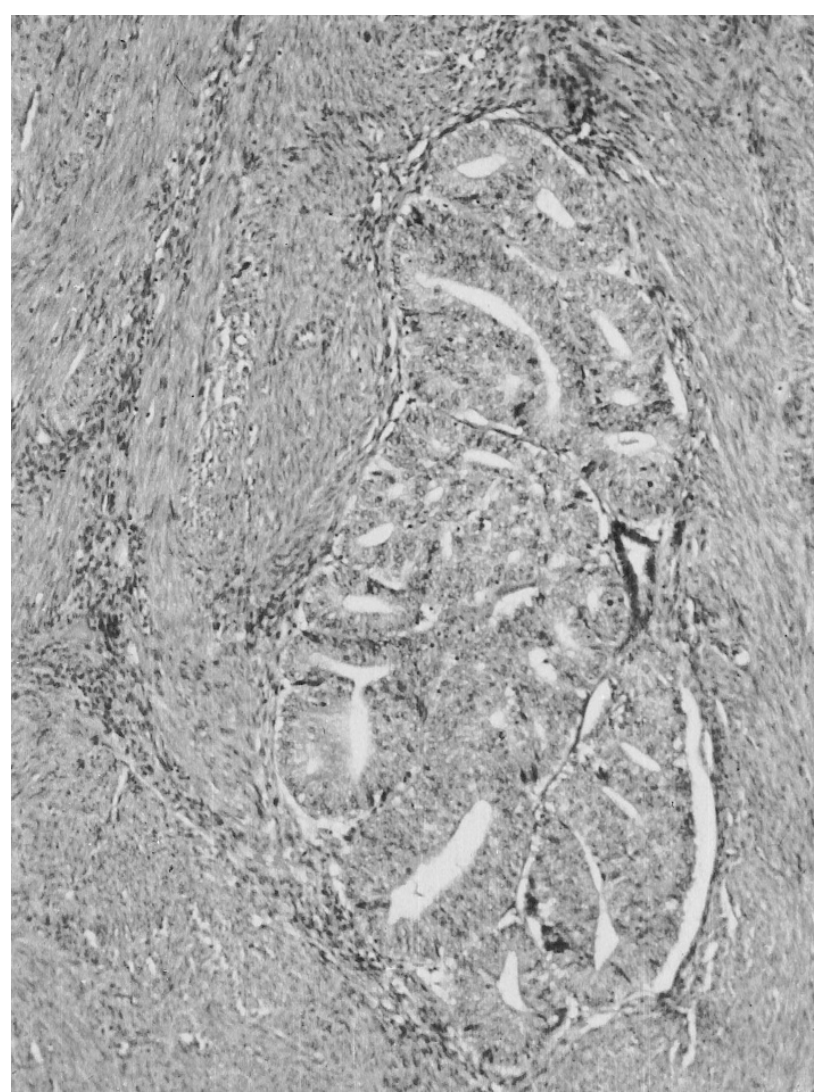

FIGURE 23. Focus of well-differentiated endometrioid adenocarcinoma within a nest of adenomyosis deep in the myometrium. Note the rounded border of the tumor, the absence of intervening reactive stroma between the malignant glands and surrounding myometrium, and the single, residual benign basalis-type gland at 3 o'clock in the tumor nest. and 24) include the following: 1) foci of adenomyosis are usually rounded, as opposed to the typically angular outlines of nests of myoinvasive carcinoma, 2) residual benign glands and/or stroma of basalis type are often present within the foci of adenomyosis involved by carcinoma, 3 ) carcinoma in adenomyosis is surrounded directly by normal myometrium, whereas myoinvasive carcinoma is often separated from the myometrium by a reactive desmoplastic stroma, and 4) the uterus in a case of endometrial carcinoma involving adenomyosis usually shows other adjacent foci of uninvolved adenomyosis, which are roughly the same size, shape, and depth within the myometrium. Occasionally, small foci of "microinvasion" out of a focus of adenomyosis into the surrounding myometrium can occur, analogous to microinvasion of cervical squamous carcinoma from an involved endocervical gland. In contradistinction to the cervix, however, there are no established rules for reporting the depth of invasion in this situation, when it occurs in an endometrial carcinoma, but one would think that, for example, $1 \mathrm{~mm}$ of such microinvasion in the outer third of the myometrium would not have the same ominous significance as other outer-third myoinvasion.

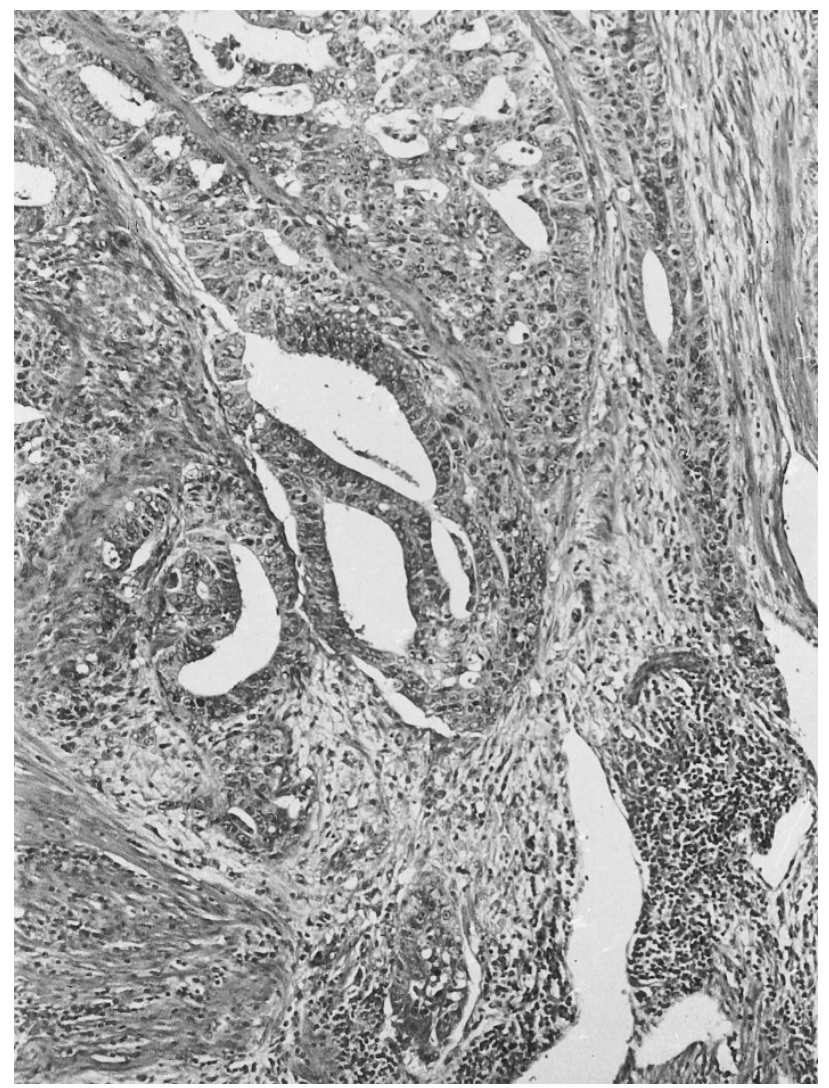

FIGURE 24. Endometrioid adenocarcinoma with true myoinvasion. Note the angulated contours of the carcinomatous glands and their separation from smooth muscle seen at lower left by reactive desmoplastic stroma. 
This presents the question of which is the best method of demonstrating and reporting myoinvasion in the uterus. There is no universally accepted number of sections to be taken from a hysterectomy specimen when endometrial carcinoma is present, but the pathologist should certainly strive to demonstrate the deepest level of myoinvasion. As mentioned previously, this determination is also frequently necessary in an intraoperative situation and requires judicious selection of the correct specimen to be frozen. Blocks submitted should always represent both the carcinoma and adjacent normal endomyometrium so that the true endomyometrial junction can be determined on the slide. Subsequent to this determination, the thickness of the myometrium to the serosal surface is determined, as is the depth of myometrial invasion by tumor. These measurements both should be expressed in the final surgical pathology report, because the clinician may want to know which third (inner, middle, outer) or half (inner, outer) of the myometrium is involved or how close to the serosal surface the tumor penetrates $(69,71,72)$. Each of these determinations can be made if the appropriate raw data are supplied.

Thus, both the grading and the determination and measurement of myometrial invasion of endometrioid adenocarcinomas of the endometrium are areas in which numerous pitfalls must be avoided by the pathologist. If these and similar determinations are made appropriately, they will contribute immeasurably to individualized patient management.

\section{REFERENCES}

1. Sherman ME. Theories of endometrial carcinogenesis: A multidisciplinary approach. Mod Pathol 2000;13:295-308.

2. Fox H. The endometrial hyperplasias. Obstet Gynecol Annu 1984;13:197-209.

3. Silverberg SG, Kurman RJ. Tumors of the uterine corpus and gestational trophoblastic disease. Atlas of Tumor Pathology. 3rd Series. Fascicle 3. Washington, DC: Armed Forces Institute of Pathology; 1992. p. 13-14.

4. Fenoglio CM, Crum CP, Ferenczy A. Endometrial hyperplasia and carcinoma. Are ultrastructural, biochemical and immunocytochemical studies useful in distinguishing between them? Pathol Res Pract 1982;174:257-84.

5. Bergeron C, Ferenczy A, Toft DO, Shyamala G. Immunocytochemical study of progesterone receptors in hyperplastic and neoplastic endometrial tissues. Cancer Res 1988;48:6132-6.

6. Duggan BD, Felix JC, Muderspach LI, Tsao JL, Shibata DK. Early mutational activation of the c-Ki-ras oncogene in endometrial carcinoma. Cancer Res 1994;54:1604-7.

7. Esteller M, Garcia A, Martinez-Palones JM, Xercavins J, Reventos J. Detection of clonality and genetic alterations in endometrial pipelle biopsy and its surgical specimen counterpart. Lab Invest 1997;76:109-16.

8. Ioffe OB, Papadimitriou JC, Drachenberg CB. Correlation of proliferation indices, apoptosis, and related oncogene expression (bcl-2 and c-erbB-2) and p53 in proliferative, hy- perplastic, and malignant endometrium. Hum Pathol 1998; 29:1150-9.

9. Levine RL, Cargile CB, Blazes MS, van Rees B, Kurman RJ, Ellenson LH. PTEN mutations and microsatellite instability in complex atypical hyperplasia, a precursor lesion to uterine endometrioid carcinoma. Cancer Res 1998;58:3524-8.

10. Maxwell GL, Risinger JI, Gumbs C, Shaw H, Bentley RC, Barrett JC, et al. Mutation of the PTEN tumor suppressor gene in endometrial hyperplasias. Cancer Res 1998;58:2500-3.

11. Mutter GL, Boynton KA, Faquin WC, Ruiz RE, Jovanovic AS. Allelotype mapping of unstable microsatellites establishes direct lineage continuity between endometrial precancers and cancer. Cancer Res 1996;56:4483-6.

12. Mutter GL, Chaponot ML, Fletcher JA. A polymerase chain reaction assay for non-random $\mathrm{X}$ chromosome inactivation identifies monoclonal endometrial cancers and precancers. Am J Pathol 1995;146:501-8.

13. Niikura H, Sasano H, Kaga K, Sato S, Yajima A. Expression of epidermal growth factor family proteins and epidermal growth factor receptor in human endometrium. Hum Pathol 1996;27:282-9.

14. Palazzo JP, Mercer WE, Kovatich AJ, McHugh M. Immunohistochemical localization of p21 WAF1/CIP1 in normal, hyperplastic, and neoplastic uterine tissues. Hum Pathol 1997;27: 60-66.

15. Rasty G, Murray R, Lu L, Kubilis P, Benrubi G, Masood S. Expression of HER-2/neu oncogene in normal, hyperplastic and malignant endometrium. Ann Clin Lab Sci 1998;28:13843.

16. Schwartz AM, Silverberg SG, Fu YS, Nozawa S, Huang S, Tsukasaki K, et al. Use of monoclonal antibodies MSN-1 and B72.3 in the prediction of the natural history of endometrial hyperplasia. Int J Gynecol Pathol 1993;12:253-8.

17. Shroyer KR, Stephens JK, Silverberg SG, Markham N, Shroyer AL, Wilson ML, et al. Telomerase expression in normal endometrium, endometrial hyperplasia, and endometrial adenocarcinoma. Int J Gynecol Pathol 1999;16:219-24.

18. Wang DP, Konishi I, Koshiyama M, Mandai M, Nanbu Y, Ishikawa $\mathrm{Y}$, et al. Expression of c-erbB-2 protein and epidermal growth receptor in endometrial carcinomas. Correlation with clinicopathologic and sex steroid receptor status. Cancer 1993;72:2628-37.

19. Winkler B, Alvarez S, Richart RM, Crum CP. Pitfalls in the diagnosis of endometrial hyperplasia. Obstet Gynecol 1984; 64:185-93.

20. Kendall BS, Ronnett BM, Isacson C, Cho KR, Hedrick L, Diener-West $\mathrm{M}$, et al. Reproducibility of the diagnosis of endometrial hyperplasia, atypical hyperplasia, and welldifferentiated carcinoma. Am J Surg Pathol 1998;22:1012-19.

21. Skov BG, Broholm H, Engel U, Franzmann MB, Nielsen AL, Lauritzen AF, et al. Comparison of the reproducibility of the WHO classifications of 1975 and 1994 of endometrial hyperplasia. Int J Gynecol Pathol 1997;16:33-7.

22. Zaino RJ. Interpretation of Endometrial Biopsies and Curettings. Philadelphia, PA: Lippincott-Raven; 1996. p. 209-12.

23. Longacre TA, Chung MH, Rouse RV, Hendrickson MR. Atypical polypoid adenomyofibromas (atypical polypoid adenomyomas) of the uterus. A clinicopathologic study of 55 cases. Am J Surg Pathol 1996;20:1-20.

24. Sherman ME, Silverberg SG. Advances in endometrial pathology. Clin Lab Med 1995;15:517-43.

25. Silverberg SG. Hyperplasia and carcinoma of the endometrium. Semin Diagn Pathol 1988;5:135-53.

26. Hendrickson MR, Ross JC, Kempson RL. Toward the development of morphologic criteria for well-differentiated adenocarcinoma of the endometrium. Am J Surg Pathol 1983;7: 819-38.

27. Kurman RJ, Norris HJ. Evaluation of criteria for distinguishing 
atypical endometrial hyperplasia from well-differentiated carcinoma. Cancer 1982;49:2547-59.

28. Tavassoli F, Kraus FT. Endometrial lesions in uteri resected for atypical endometrial hyperplasia. Am J Clin Pathol 1978; 70:770-9.

29. Longacre TA, Chung MH, Jensen DN, Hendrickson MR. Proposed criteria for the diagnosis of well-differentiated endometrial carcinoma. A diagnostic test for myoinvasion. Am J Surg Pathol 1995;19:371-406.

30. Silverberg SG, deGiorgi LS. Histopathologic analysis of preoperative radiation therapy in endometrial carcinoma. Am J Obstet Gynecol 1974;119:698-704.

31. Hunter JE, Tritz DE, Howell MG, DePriest PD, Gallion HH, Andrews SJ, et al. The prognostic and therapeutic implications of cytologic atypia in patients with endometrial hyperplasia. Gynecol Oncol 1994;55:64-71.

32. Jacques SM, Qureshi F, Munkarah A, Lawrence WD. Interinstitutional surgical pathology review in gynecologic oncology: endometrial cancer in hysterectomy specimens. Int J Gynecol Pathol 1998;17:42-5.

33. Silver SA, Sherman ME. Morphologic and immunophenotypic characterization of foam cells in endometrial lesions. Int J Gynecol Pathol 1998;17:140-5.

34. Dawagne MP, Silverberg SG. Foam cells in endometrial carcinoma: a clinicopathologic study. Gynecol Oncol 1982;13:67-75.

35. Copenhaver EH. Atypical endometrial hyperplasia. Obstet Gynecol 1959;13:264-8.

36. Hertig AT, Sommers SC, Bengloff H. Genesis of endometrial cancer. I. A study of prior biopsies. Cancer 1949;2:946-56.

37. Telinde RW, Jones HW Jr, Galvin GA. What are the earliest endometrial changes to justify a diagnosis of endometrial cancer? Am J Obstet Gynecol 1953;66:953-69.

38. Ferencyz A, Gelfand M. The biologic significance of cytologic atypia in progestogen-treated endometrial hyperplasia. Am J Obstet Gynecol 1989;160:126-31.

39. Kurman RJ, Kaminski PF, Norris HJ. The behavior of endometrial hyperplasia: a long term study of "untreated" hyperplasia in 170 patients. Cancer 1985;56:403-12.

40. Baak J, Wisse-Brekelmans E, Fleege J, van der Putten H, Bezemer P. Assessment of the risk on endometrial cancer in hyperplasia, by means of morphological and morphometrical features. Pathol Res Pract 1992;188:856-9.

41. Huang SJ, Amparo EG, Fu YS. Endometrial hyperplasia: histologic classification and behavior. Surg Pathol 1988;1:215-29.

42. Sherman AI, Brown S. The precursors of endometrial carcinoma. Am J Obstet Gynecol 1979;135:947-56.

43. Boyd J. Molecular biology in the clinicopathologic assessment of endometrial carcinoma subtypes. Gynecol Oncol 1996;61:163-5.

44. Sherman ME, Bur ME, Kurman RJ. p53 in endometrial cancer and its putative precursors: evidence for diverse pathways of tumorigenesis. Hum Pathol 1995;26:1268-74.

45. Sherman ME, Sturgeon S, Brinton LA, Potischman N, Kurman RJ, Berman ML, et al. Risk factors and hormone levels in patients with serous and endometrioid uterine carcinomas. Mod Pathol 1997;10:963-8.

46. Sivridis E, Fox H, Buckley CH. Endometrial carcinoma: two or three entities? Int J Gynecol Cancer 1998;8:183-8.

47. Soslow RA, Shen PU, Chung MH, Isacson C. Distinctive p53 and $\mathrm{mdm} 2$ immunohistochemical expression profiles suggest different pathogenetic pathways in poorly differentiated endometrial carcinoma. Int J Gynecol Pathol 1998;17:129-34.

48. Tobon H, Watkins GJ. Secretory adenocarcinoma of the endometrium. Int J Gynecol Pathol 1985;4:328-35.

49. Hendrickson MR, Kempson RL. Ciliated carcinoma: a variant of endometrial cancer: a report of 10 cases. Int J Gynecol Pathol 1983;2:1-12.

50. Maksem JA. Ciliated cell adenocarcinoma of the endometrium diagnosed by endometrial brush cytology and con- firmed by hysterectomy: a case report detailing a highly efficient cytology collection and processing technique. Diagn Cytopathol 1997;16:78-82.

51. Novak ER, Nalley WB. Uterine adenoacanthoma. Obstet Gynecol 1957;9:396-402.

52. Ng AB, Reagan JW, Storaasli JP, Wentz WB. Mixed adenosquamous carcinoma of the endometrium. Am J Clin Pathol 1973;59:765-81.

53. Silverberg SG. Significance of squamous elements in carcinoma of the endometrium: a review. Prog Surg Pathol 1982; 4:115-36.

54. Zaino RJ, Kurman R, Herbold D, Gliedman J, Bundy BN, Voet $\mathrm{R}$, et al. The significance of squamous differentiation in endometrial carcinoma: data from a Gynecologic Oncology Group study. Cancer 1991;68:2293-302.

55. Esteller M, Garcia A, Martinez-Palones JM, Xercavins J, Reventos J. Clinicopathologic features and genetic alterations in endometrioid carcinoma of the uterus with villoglandular differentiation. Am J Clin Pathol 1999;111:33642.

56. Kallakury VSB, Ambros RA, Hayner-Buchan AM, Sheehan CE, Malfetano JH, Ross JS. Cell proliferation-associated proteins in endometrial carcinomas, including papillary serous and endometrioid subtypes. Int J Gynecol Pathol 1998;17: $320-6$.

57. Zaino RJ, Kurman RJ, Brunetto VL, Morrow CP, Bentley RC, Cappellari JO, et al. Villoglandular adenocarcinoma of the endometrium. A clinicopathologic study of 61 cases: a Gynecologic Oncology Group study. Am J Surg Pathol 1998;22: 1379-85.

58. Maggino T, Romagnolo C, Landoni F, Sartori E, Zola P, Gadducci A. An analysis of approaches to the management of endometrial cancer in North America: a CTF study. Gynecol Oncol 1998;68:274-9.

59. Sherman ME, Bitterman P, Rosenshein NB, Delgado G, Kurman RJ. Uterine serous carcinoma. A morphologically diverse neoplasm with unifying clinicopathologic features. Am J Surg Pathol 1992;16:600-10.

60. Zaino RJ, Kurman RJ, Diana KL, Morrow CP. The utility of the revised International Federation of Gynecology and Obstetrics histologic grading of endometrial adenocarcinoma using a defined nuclear grading system: a Gynecologic Oncology Group study. Cancer 1995;75:81-6.

61. Hachisuga T, Kawarabayashi T, Iwasaka T, Sugimori H, Kamura $\mathrm{T}$, Tsuneyoshi $\mathrm{M}$. The prognostic value of semiquantitative nuclear grading in endometrial carcinomas. Gynecol Oncol 1997;65:115-20.

62. Taylor RR, Zeller J, Lieberman RW, O'Connor DM. An analysis of two versus three grades for endometrial carcinoma. Gynecol Oncol 1999;74:3-6.

63. Creasman W, Odincino F, Maisonneuve P, Benefet J, Shepherd J, et al. Carcinoma of the corpus uteri: Annual report on the results of treatment in gynaecological cancer. J Epidemiol Biostat 1998;3:46-7.

64. Morrow CP, Bundy BN, Kurman RJ, Creasman WT, Heller P, Homesley $\mathrm{HD}$, et al. Relationship between surgicalpathological risk factors and outcome in clinical stage I and II carcinoma of the endometrium: a Gynecologic Oncology Group study. Gynecol Oncol 1991;40:55-65.

65. Jones, HW. The importance of grading in endometrial cancer. Gynecol Oncol 1999;74:1-2.

66. Malviya VK, Deppe G, Malone JM Jr, Sundareson AS, Lawrence WD. Reliability of frozen section examination in identifying poor prognostic indicators in stage I endometrial adenocarcinoma. Gynecol Oncol 1989;34:299-304.

67. Atad J, Weill S, Ben-David Y, Hallak M, Klein O, Lurie M, et al. Intraoperative frozen section examination of myometrial invasion depth in patients with endometrial carcinoma. Int J Gynecol Cancer 1994;4:352-5. 
68. Seidman JD, Kjerulff KH. Pathologic findings from the Maryland Women's Health Study: practice patterns in the diagnosis of adenomyosis. Int J Gynecol Pathol 1996;15:217-21.

69. Mittal KR, Barwick KW. Endometrial adenocarcinoma involving adenomyosis without true myometrial invasion is characterized by frequent preceding estrogen therapy, low histologic grades, and excellent prognosis. Gynecol Oncol 1993;49:197-201.

70. Longacre TA, Hendrickson MR. Diffusely infiltrative endo- metrial adenocarcinoma: an adenoma malignum pattern of myoinvasion. Am J Surg Pathol 1999;23:69-78.

71. Robboy SJ, Bentley RC, Krigman H, Silverberg SG, Norris HJ, Zaino RJ. Synoptic reports in gynecologic pathology. Int J Gynecol Pathol 1994;13:161-74.

72. Silverberg SG. Protocol for the examination of specimens from patients with carcinomas of the endometrium: a basis for checklists. Cancer Committee, College of American Pathologists. Arch Pathol Lab Med 1999;123:28-32.

\section{Book Review}

\section{Rubanyi GM (ed): Angiogenesis in Health and Disease: Basic Mechanisms and Clinical Applications, 552 pp, New York, Marcel Dekker, 2000 (\$195).}

This monograph contains 33 chapters dealing with various aspects of angiogenesis, a very hot research topic for which, unfortunately, I have only peripheral vision. Nevertheless, I perused the book with interest, which allowed me to improve somewhat my understanding of this extremely complex but apparently crucial biologic phenomenon. Above all, it convinced me that books of this type serve a function in educating people who are not working a specific field of inquiry. As such, I recommend it as an addition to your general medical library.

Most of the chapters that I chose to read were well written and informative. The one that I liked the most was the introductory overview by I. Flamme on the molecular biology of vasculogenesis and early angiogenesis. I also learned about various inhibitors and promotors of angiogenesis and the incredible amount of work done in experimental animals, or in vitro, as well as in clinical settings. The story of thalidomide, which made an astonishing comeback, is revealing in itself. At the same, however, it shows how fast books of this kind become outdated: while the book is quoting a 1998 news report about the "new breakthrough from Arkansas," by now we already know that thalidomide has been extensively tested in the treatment of human multiple myeloma.

Books of this type have a short half-life and rapidly become obsolete. Nevertheless, they serve a useful function and should be in major libraries for people who want to learn about a given topic from experts in the field.

\section{Ivan Damjanov \\ University of Kansas School of Medicine \\ Kansas City, Kansas}

